\title{
Competitive Pressure and the Adoption of Complementary Innovations
}

\author{
By Tobias Kretschmer, Eugenio J. Miravete, and José C. Pernías*
}

Liberalization of the European automobile distribution system in 2002 limits the ability of manufacturers to impose vertical restraints, leading to a substantial increase in competitive pressure among dealers. We estimate an equilibrium model of profit maximization to evaluate how dealers change their innovation adoption strategies following the elimination of exclusive territories. Using French data we evaluate the existence of complementarities between the adoption of software applications and the scale of production. Firms view these innovations as substitutes and concentrate their effort in one type of software as they expand their scale of production. Results are robust to the existence of unobserved heterogeneity. (JEL: C35, L86, O31).

Keywords: Competitive Pressure, Complementarity, Interdependent Innovations.

The question of how the intensity of competition in a market affects firm incentives to improve their products and/or reduce unit costs is a long-standing one in economics. As continued innovation ultimately determines the growth possibilities of an economy, policies aimed at increasing the (static) competitiveness of a market also have to be evaluated considering their impact on long-term innovativeness of a sector or an economy. Since incentives to innovate depend on the rents expected by an innovative firm, there has been a lively debate as to which market structure is most conducive to innovative behavior. Much of this debate has focused on a single dimension of innovative activity despite innovation typically being a complex process involving multiple decisions and stages. Our paper contributes to this debate by addressing some of these aspects. It aims to capture the third part of the Schumpeterian trilogy - the diffusion or adoption of innovations - and recognizes that potential adopters of innovations can choose among different innovations.

\footnotetext{
* Kretschmer: Ludwig-Maximilians-Universität-München, Institute for Strategy, Technology and Organization and ifo Institute, Schackstraße. 4/III. D-80539 München, Germany, t.kretschmer@lmu.de. Miravete: The University of Texas at Austin, Department of Economics and CEPR, BRB 1.116, 1 University Station C3100, Austin, Texas 787120301, miravete@eco.utexas.edu. Pernías: Universidad Jaume I de Castellón, Av. de Vicente Sos Baynat s/n, 12071 Castellón, Spain, Jose.Pernias@ uji.es. We thank the constructive comments of a referee as well as those of Jason Abrevaya, John Asker, Jonathan Beck, Kenneth Hendricks, Claudio Piga, Howard Smith, Stefan Wiegand of KPMG, and seminar participants at Freie Universität Berlin, U.S. Federal Communications Commission, Universities at Alicante, Lisbon (Técnica), Kyoto, Munich, Odense, Texas-Austin, Utrecht, and WZB, as well as the LACEA/LAMES meeting in Rio de Janeiro, the 2009 Winter Workshop at the Centre for Competition and Regulatory Policy at City University London, the 10th CEPR Applied IO Conference in Mannheim, the 3rd RNIC on "Competition Policy and Innovation" in Vienna, and the 2011 SEEK kick-off Conference at ZEW in Mannheim. Funding from the NET Institute is gratefully acknowledged. Kretschmer thanks the Anglo-German Foundation and the Research Council of Norway for financial support and UT Austin and NYU Stern for their hospitality. Miravete thanks the generous hospitality of the Institute for Strategy, Technology and Organization. Pernías thanks the financial support of the Spanish Ministry of Science (ECO2008-06057/ECON) and Generalitat Valenciana (GV/2009/057).
} 
We limit our study to a particular industry setting, the French car dealer industry, and consider the adoption of two different software technologies, triggered by a change in regulation in the industry aimed at increasing the competitiveness of the automobile retail distribution system. This is interesting for several reasons. First, existing studies pay little attention to the "users" of an innovation. Thus, while we would not typically think of car dealers as innovators in the software industry, the ultimate contribution of information and communication technologies (ICT) on economic growth will depend on the extent to which they diffuse throughout the economy. Second, the adoption of different software technologies may be "interdependent." That is, adoption of one technology may make the adoption of others more attractive if they are complements, or adoption of one may foreclose adoption of another if they are substitutes in their functionality or if the firm's budget constraint does not permit adoption of both. Third, rather than relying on variations across different industries with unobserved structural differences, we capture a change in competitive intensity through a regulatory regime change "in a single industry." To our knowledge, this is the first time that the effect of competition has been measured in this way rather than pooling heterogeneous industries or countries with different numbers of competitors.

What is the effect of an increase in competitive pressure on innovation? How is competitive pressure transmitted if firms choose multiple strategies simultaneously? Our approach to answering these questions builds on four basic pillars: (i) we distinguish between two potential innovations to be adopted: human resource management software, HR, and applications development software, APPS; (ii) we allow firms to make innovation adoption decisions simultaneously with other strategies, most importantly the scale of production; (iii) we let these strategies generate return synergies (either positive or negative) when used jointly; and (iv) our estimations control for the possibility that unobservable factors drive the observed correlations among firms' decision variables.

We distinguish two types of software innovations, APPS and HR software. Joseph A. Schumpeter (1934) argued that market power favors cost reducing innovations because larger firms may enjoy economies of scale while Kenneth J. Arrow (1962) envisioned competitive environments as providing the right incentives to adopt demand enhancing innovations that help firms effectively differentiate their product offerings. Hence, many theoretical models arrive at conflicting predictions regarding the effect of market structure on the innovativeness of firms. In his overview, Richard Gilbert (2006) argues that competition may reduce the incentive to innovate if intellectual property rights are nonexclusive but will foster innovation if they are exclusive. Armin Schmutzler (2010) identifies the countervailing effect of own demand shifts following a competitor adopting a cost-reducing innovation if products are complements, although the effect becomes reinforcing if they are substitutes. Finally (although this review is not exhaustive), Xavier Vives (2008) stresses that incentives to innovate in competitive or monopolistic settings depend on whether entry is free or restricted. Not surprisingly therefore, Gilbert (2006, $\S$ I) notes that "... empirical studies rarely account for the many factors that the theory suggests should be significant determinants of innovative activity." Indeed, Gilbert (2006, §II) acknowledges that "it is not that we don't have a model of market structure and $R \& D$, but rather that we have many models and it is important to know which model 
is appropriate for each market context." Consequently, rather than pooling data across industries and countries, our empirical approach focuses on a specific industry to avoid these criticisms. ${ }^{1}$

Innovations are only one of the many strategies that firms choose together with production, pricing, advertising, et cetera. Following Paul R. Milgrom and John Roberts (1990), we treat firms as organizational systems where several decisions are made in a coordinated manner. Firms will then benefit from taking into account the potential synergies that one strategy may have on the returns to other strategies. The scale of production is typically an explanatory variable for innovation activities in evaluating whether larger firms have an advantage over small ones in developing and adopting innovations, and thus supporting or refuting the Schumpeterian hypothesis. ${ }^{2}$ However, the minimum efficient scale of production may change with the adoption of innovations. This issue has far more important consequences than just dealing with the potential endogeneity bias of treating the scale of production as exogenous. ${ }^{3}$ Actually, (positive or negative) complementarities may also exist across scale and innovation adoption strategies. Through such complementarities, competition may not only directly affect the returns to innovate, but also lead to changes in the optimal scale of production triggering more (or less) innovations of each kind.

To account for all these different aspects of innovative activity our econometric model adopts the setup of Eugenio J. Miravete and José C. Pernías (2006). We use a flexible functional form to accommodate discrete strategies such as APPS and HR software adoption in addition to the contemporaneous scale of production and the outcome (profits) of any other unobserved strategies. This flexible approach let the data determine whether the profit function is supermodular in all or some of the choice variables, thus leading to the existence of complementarities among the appropriate strategies. ${ }^{4}$ We also allow for the existence of unobserved heterogeneity in the form of unobserved returns to the firms'

\footnotetext{
${ }^{1}$ To identify the effect of competitive pressure, researchers have used data sets that include several industries with different degrees of competition, or the same industry across different countries. A general concern with these approaches is that econometric models fail to be closely linked to the institutional features of any industry in particular and results are suspicious of being driven by aggregation across industries and countries. For instance, Philippe Aghion, Richard W. Blundell, Rachel Griffith, Peter Howitt and Susan Prantl (2004) use a micro-level panel data of U.K. firms from several industries to evaluate the effect of foreign entry on domestic patenting decisions; Irene Bertschek (1995) analyzes how imports and inward foreign direct investment affects product and process innovation across industries in West Germany; Wendy Carlin, Mark E. Schaffer and Paul Seabright (2004) evaluate the innovation performance of several State owned firms in twenty-four transition countries; and James M. MacDonald (1994) studies how the rate of growth of labor productivity changes with import penetration using data from ninety-four industries in the 1972-1987 period. Two notable exceptions are the works of José E. Galdón-Sánchez and James A. Schmitz (2002), who make use of a well defined natural experiment in the iron-ore market, and Richard W. Blundell, Rachel Griffith and John Van Reenen (1999), who make use of lagged information in a panel data estimation to control for the endogeneity and simultaneity of $R \& D$ expenditures and market structure.

${ }^{2}$ Wesley M. Cohen and Steven Klepper (1996) consider the theoretical relationship between firm size and type of innovation although functional form assumptions drive many of the testable implications. Most importantly, scale is treated as an exogenous variable in their econometric specification.

${ }^{3}$ Thomas J. Holmes, David K. Levine and James A. Schmitz (2008) argue that it is precisely this simultaneity what leads monopolistic firms to have a lower incentive to adopt innovations than competitive ones. The reason is that adopting a cost-reducing innovation requires a temporary reduction in scale — "switchover disruptions" in their terminology—and since monopolies forego larger rents with every unit temporarily lost than competitive firms, they tend to postpone such innovation decisions.

${ }^{4}$ Using a flexible functional form aims at avoiding misspecification arising from restrictive functional forms that cannot accommodate certain innovation patterns. See Vives (2008, §III(iii)).
} 
strategies, which are freely correlated with each other. We derive the optimal scale and innovation strategies from maximizing this profit function and employ an equilibrium approach to estimate the model.

We want to evaluate the impact of competitive pressure on the adoption of different kinds of innovations and identify how this effect is transmitted within a single industry. Our approach to account for an increase in competitive pressure is to use an exogenous shift in regulatory regime, the passing of E.U. Regulation 1400/2002 which affects the nature of competition but not the appropriability of the rents of innovation. ${ }^{5}$ This exogenous regulatory shift of the automobile distribution system in Europe facilitates entry (mostly of Asian manufacturers) and more aggressive commercial practices in the automobile dealership industry after 2002. Essentially, this regulation had the unanticipated effect of removing exclusive territories from the set of allowed vertical restraints between automobile manufacturers and dealers. Patrick Rey and Joseph Stiglitz (1995) show that this makes manufacturers believe they face more elastic demand, thus inducing a decrease in equilibrium prices and manufacturers' profits. Further, downstream dealers find their monopoly rents reduced and compete more fiercely with other dealers in neighboring markets. We therefore argue that such liberalization increases inter- and intra-brand competition and affects how competitive the market for dealers is, which in turn may affect the incentive to adopt an innovation.

Our results show that the direct effect of increasing competitive pressure is to increase dealers' sales and the likelihood of adopting HR software. Moreover, we document the existence of complementarity effects. Liberalization of the automobile distribution industry in France leads to an increase in optimal dealer scale, which in turn facilitates the adoption of APPS software but not HR software. However, there is a strong negative complementarity between APPS and HR software innovations. Thus, software innovations appear to be substitutes and dealers specialize in adopting only one of the two, most likely HR given the direct effect of increased competition on the return to adopting it. These results are robust to the existence of unobserved returns to each strategy, as well as the definition of local markets, their size, their urbanization, and any possible anticipation of the liberalization process that took place in the European automobile distribution system in September 2002.

The rest of the paper is organized as follows. Section I reviews the institutional details of the European automobile distribution system and its liberalization in September 2002. This section also describes the adoption decisions we study and presents preliminary evidence on the existence of complementarities. Section II introduces the econometric model and discusses its coherence and identification. Section III reports the estimates for different specifications, each successively relaxing restrictions on the existence of complementarities and unobserved heterogeneity. We then conduct various specification tests and discuss the estimation bias for an increase in competitive pressure if complementarities were ignored. We also evaluate the direct and indirect effects of an increase in competitive pressure on all strategies by simulating firms' profiles and evaluating them

\footnotetext{
${ }^{5}$ The direct effect of antitrust regulation on innovation is a largely unexplored area. An exception is the work of Ilya R. Segal and Michael D. Whinston (2007) who consider how more or less protective policies toward entrants affect the overall innovation in a model with successive generations of entrants who turn into incumbents and incumbents who eventually leave the industry.
} 
at the parameter estimates and firm and market characteristics. Section IV concludes.

\section{Data and Institutional Background}

We study French car dealerships between 2000 and 2004. The change in E.U. regulation in September 2002 constitutes an interesting natural experiment that provides us with an unusual measure of increased competitive pressure, as territorial exclusivity was suddenly abandoned as permissible vertical restraint. While a change of regulation was largely anticipated, its specific implementation (the effective abolishment of territorial exclusivity) was not. This lets us study how an increase in competitive pressure affects scale and different innovation choices, both directly on their associated returns, and indirectly through the potential complementarities among all these strategies. This section covers four issues regarding our dealer level data on output, software adoption, and profits: (i) we review the institutional details surrounding the change in the regulatory framework of the automobile distribution system in Europe; (ii) we discuss how the change in regulation translates into an increase in competitive pressure at the dealer segment of the market; (iii) we describe the nature of software innovations and give indicative evidence of the existence of complementarities among strategies; and (iv) we provide some evidence that the change in innovation activity is mostly related to the change in regulatory framework rather than to other likely causes.

\section{A. Liberalization of the European Automobile Distribution System}

For many years, vertical restraints in the automobile distribution industry were exempt from antitrust enforcement as European authorities gave in repeatedly to the industry's demands. ${ }^{6}$ Regulation 1400/2002 aimed at increasing competition by "allow[ing] distributors [... ] to seize additional business opportunities." After Regulation 1400/2002 was passed shortly before September 2002, automobile manufacturers had to choose between selectivity and territorial exclusivity in commercial relations with dealers. "Selectivity" aims at imposing a minimum quality of service and allows automobile manufacturers to require from dealers a minimum level of staff training, advertising, storage, and most importantly the obligation to provide after-sales repair and maintenance services. "Territorial Exclusivity" refers to the manufacturers' right to allow only one dealer in a given geographical area. Together, selectivity and territorial exclusivity reduce not only the total number of dealers but also reduce opportunities for more efficient dealers to capture larger market shares. After 2002, most manufacturers chose to enforce selective vertical restraints only, which led dealers to open other domestic and foreign branches and to intensify competition across markets. ${ }^{7}$

\footnotetext{
${ }^{6}$ This subsection draws on Randy Brenkers and Frank Verboven $(2006, \S 1-2,8)$ and Frank Verboven $(2008, \S 2.3)$, as well as on the data collected by London Economics in its June 2006 report to the EC DG Competition on "Developments in Car Retailing and After-Sales Markets Under Regulation No. 1400/2002."

${ }^{7}$ Selectivity also restricts dealers to sell automobiles only to final consumers and not to non-authorized intermediaries or dealers outside the manufacturers' networks. Furthermore, under territorial exclusivity dealers, are not allowed to own branches of their dealerships outside the exclusive territory and their advertising efforts should be aimed primarily at this specific market. Only Suzuki, a very small player in the French automobile market, chose to enforce territorial exclusivity
} 
TABle 1 -SAMPle Distributions of Endogenous VARIABles

\begin{tabular}{|c|c|c|c|c|c|c|}
\hline & \multicolumn{2}{|c|}{ All periods } & \multicolumn{2}{|c|}{ Pre-Expiry } & \multicolumn{2}{|c|}{ Post-Expiry } \\
\hline & Mean & S.D. & Mean & S.D. & Mean & S.D. \\
\hline$x_{a}$ & 0.066 & 0.248 & 0.076 & 0.266 & 0.046 & 0.209 \\
\hline$x_{h}$ & 0.171 & 0.376 & 0.160 & 0.367 & 0.192 & 0.395 \\
\hline$x_{y}$ & 3.088 & 1.666 & 2.987 & 1.698 & 3.283 & 1.588 \\
\hline$\pi$ & 18.103 & 97.149 & 18.443 & 97.995 & 17.452 & 95.725 \\
\hline$N$ & \multicolumn{2}{|c|}{639} & \multicolumn{2}{|c|}{420} & \multicolumn{2}{|c|}{219} \\
\hline
\end{tabular}

Means and standard deviations of endogenous variables by competition regime. Innovation indicators are dummy variables. Scale is measured in logarithm of thousands of euros while profits are measured in thousands of euros. $N$ denotes the number of dealers in each sample.

Is this change in regulation a good proxy for the increase in competitive pressure among European automobile dealers? Expiration of Regulation 1475/95 was largely predictable but the fact that manufacturers must choose between selectivity and territorial exclusivity was not anticipated. Moreover, the change in regulation has little to do with the innovation proneness of automobile retailers but rather with the retail price setting mechanism. As Gilbert (2006, §III) recommends, this regime shift does not affect determinants of innovations such as technological opportunity. Hence, years 2003 and 2004 (LIB dummy variable) identify the period where competition is more intense after the liberalization of the European automobile distribution system. ${ }^{8}$

Table 1 presents basic descriptive statistics for our four endogenous variables across the entire sample for pre- and post-expiry periods of the EU exemption: adoption of APPS software $\left(x_{a i}\right)$; adoption of HR software $\left(x_{h i}\right)$; scale $\left(x_{y i}\right)$; and accounting profits, $\left(\pi_{i}\right)$ capturing the effects of all strategies including others different than $\left\{x_{y i}, x_{a i}, x_{h i}\right\}$. Note the substantial increase in HR software adoption and scale of production after the new regulatory framework is adopted. Similarly, there is an important reduction in the rate of APPS software adoption and a slight decrease in profits consistent with the increased competition argument.

\section{B. Increase in Competitive Pressure}

How does the removal of the exclusive territory restraint increase competition among dealers? A short answer is that competition increases because they can now compete outside their limited initial territories. As they get in contact with other dealers of the same brand they have to offer lower retail prices to final customers, reducing inter-regional

\footnotetext{
at the expense of selectivity. Hence, Suzuki dealers became free to sell to independent resellers that were not necessarily in the manufacturers' networks.

${ }^{8}$ It is interesting to note that France and Italy were among the latest markets to embrace the restructuring of their automobile distribution networks. This makes France a better object of study than many other European countries where this liberalization process was already on its way by the time the European regulation was adopted.
} 
price differences. ${ }^{9}$

A more elaborate answer incorporates the change in wholesale competition inflicted by the change in regulation and how manufacturers' behavior is altered once the market in which dealers operate expands and downstream competition intensifies. The argument is made explicit in the work of Rey and Stiglitz (1995), who show that exclusive territories are an effective tool to help manufacturers soften upstream competition but they also serve to increase both retail and wholesale price. Their model of horizontally differentiated products closely mimics the main features of the automobile industry. Within an exclusive territory, retail prices of substitute goods are strategic complements and thus an increase by one of the dealers triggers a retail price increase by competitors. In equilibrium the competing manufacturers will charge a higher wholesale price to capture monopolistic rents, i.e., exclusive territories lead to weaker downstream intrabrand competition, which in turn implies weaker upstream interbrand competition. Removing the exclusive territory constraint produces the opposite effects. Absent exclusive territories, dealers account for demand potentially being diverted towards neighboring markets, thus increasing downstream intrabrand competition. This change in competition regime allows us to identify the effect of competitive pressure on the likelihood that dealers adopt different innovations. We also know that interbrand competition intensifies among manufacturers although we do not make use of it in our empirical analysis. ${ }^{10}$

This increase in competitiveness at the dealer level is a complex process that goes beyond the simple removal of a vertical restraint and the ability to soften competition among manufacturers. Until 2002 there were "main dealers" and "sub-dealers." Main dealers had contracts with car manufacturers while sub-dealers held contracts with a main dealer, who supplied them with parts, vehicles, and technical support. After 2002 mostly sub-dealers left the distribution network. In France the total number of dealerships fell by 21 percent between 2002 and 2003 alone and 31 percent, from 18,202 to 12,512 between 2000 and 2004. Similarly, dealer density dropped from around 32 to just over 20 dealers per thousand inhabitants. This is the most important reduction of the size of the dealer network and dealer density in any E.U. member state following the change in regulatory framework, which led to an increase in sales per dealer captured in the third row of Table $1 .{ }^{11}$

These observations may appear at odds with our claim that the removal of exclusive territory restraint increases competitive pressure. However, note that the definition of relevant market has changed and is not limited to the original exclusive territory. ${ }^{12}$ Indeed,

\footnotetext{
${ }^{9}$ Pinelopi K. Goldberg and Frank Verboven (2001) and Frank Verboven (1996) document the extensive use of price discrimination in the automobile industry across European markets.

${ }^{10}$ Regulation 1400/2002 was also aimed at increasing competition and efficiency both at the manufacturer and the retailer level. See Section 10 of Commission Regulation (EC) No 1400/2002 of 31 July 2002 on the application of Article 81(3) of the Treaty to Categories of Vertical Agreements and Concerted Practices in the Motor Vehicle Sector at http://eur-lex.europa.eu/LexUriServ/LexUriServ.do?uri=CELEX:32002R1400:EN:NOT.

${ }^{11}$ See chapters 40 and 37, respectively, of "Developments in Car Retailing and After-Sales Markets under Regulation No. 1400/2002," Volume I, Final Report to EC DG Competition by London Economics. European Communities, Brussels. Sales increase in our sample by 10 percent between 2000-2002 and 2003-2004; a similar rate to the rest of the industry. See European Car Distribution Handbook, HWB International, issues 2000 to 2005, Milford-on-Sea, U.K.

${ }^{12}$ Jan Boone (2000a) and Jan Boone (2000b) argue that even if the definition of the relevant market does not change, a market configuration with fewer firms may lead to a more competitive outcome even without horizontal product differ-
} 
fewer firms compete more aggressively in larger markets, therefore limiting the ability to raise prices and markups. Two more issues helped facilitate competition among brands in the automobile distribution industry in Europe after September 2002: First, Asian manufacturers entered by taking over locations abandoned by former sub-dealers; and second, the proportion of multibrand retailers also increased in France from 10.2 percent in 2000-2002 to 17.5 percent in 2003-2004. According to the assessment of Regulation $1400 / 2002$, this "proliferation of multibrand dealerships represents a positive development from the point of consumers." 13 In short, Regulation 1400/2002 increased "intrabrand" competition by allowing dealers of the same brand to compete in each other's territory and "inter-brand" competition by relaxing the restriction that dealers only sell one brand of car.

\section{Software Adoption in Automobile Retailing}

Data include innovation strategies, sales, and accounting profits of the "Motor Vehicle Dealers" industry (SIC code 5511) in France from 2000 to 2004. Each cross-section (year) includes a representative sample of automobile dealerships. We focus on the French market because data are comprehensive, collected with a consistent methodology, and available for a large number of well defined markets. French dèpartements define areas with fairly homogeneous market conditions. In addition, the large number of dèpartements (about a hundred) lets us benefit from significant regional diversity. Section V enumerates the data sources and describes the sampling methodology.

We study the adoption of two software packages, namely human resource management software HR, and applications development software APPS. HR management software refers to a range of software applications that regulate all the personnel related data flow, such as tracking employees' participation in benefits programs, administering the recruiting process, and implementing human resource practices more efficiently. In essence, HR software supports human resource processes that were previously administered manually. This facilitates savings on administrative expenses, especially personnel. For example, in the car dealer industry sales personnel is paid partly by commission, for which an entry has to be made on the payroll every time a car sale is made. Variable $x_{h i}$ accounts for the adoption of HR software in our econometric model.

APPS development software grew out of programming languages such as $\mathrm{C}++$, Basic, or Fortran with added functionality like debugging or requirements testing to facilitate the development of own, customized software applications. APPS effectively provides a user interface and toolbox for programmers. ${ }^{14}$ Adopting APPS development software enables firms to develop IT infrastructure that can easily be scaled up to serve multiple locations. For example, firm-specific advanced replenishment systems for spare parts facilitates stocking different outlets and serving diverse consumer groups, enabling firms

entiation if firms are not equally efficient, so that more efficient firms are in a better position to draw demand away from less efficient competitors, who may subsequently exit the industry.

${ }^{13}$ P. 90, "Developments in Car Retailing and After-Sales Markets under Regulation No. 1400/2002," Volume I, Final Report to EC DG Competition by London Economics. European Communities, Brussels.

${ }^{14}$ The most prominent examples of application development software are Microsoft's Visual Basic at the low end and Borland's Delphi at the high end. 
TABle 2-Distribution of InNOVATION Profiles

\begin{tabular}{|c|c|c|c|c|c|c|c|c|c|}
\hline & \multicolumn{3}{|c|}{ All periods } & \multicolumn{3}{|c|}{ Pre-Expiry } & \multicolumn{3}{|c|}{ Post-Expiry } \\
\hline & share & $\bar{x}_{y}$ & $\bar{\pi}$ & share & $\bar{x}_{y}$ & $\bar{\pi}$ & share & $\bar{x}_{y}$ & $\bar{\pi}$ \\
\hline None & 77.2 & 2.98 & 20.1 & 77.1 & 2.88 & 20.6 & 77.2 & 3.19 & 19.0 \\
\hline Only APPS & 5.8 & 3.44 & 5.0 & 6.9 & 3.37 & 5.2 & 3.7 & 3.70 & 4.1 \\
\hline Only HR & 16.3 & 3.34 & 10.8 & 15.2 & 3.24 & 11.3 & 18.3 & 3.48 & 9.9 \\
\hline Both & 0.8 & 5.54 & 74.9 & 0.7 & 5.62 & 64.9 & 0.9 & 5.41 & 90.0 \\
\hline
\end{tabular}

Percentage of firms adopting every possible combination of innovations. Scale is measured in logarithm of thousands of euros while profits are measured in thousands of euros.

to grow and increase revenues more easily. Such systems are typically developed inhouse with the help of APPS development software to incorporate the specifics of their business. ${ }^{15}$ Further, internet applications prove critical not only in providing information about models, but also scheduling test-drives, checking availability, and finding out about financing conditions. A recent study indicates that 30 percent of French customers are more likely to purchase a vehicle from a particular manufacturer if they are satisfied with the features of its website. ${ }^{16}$ Thus, adopting APPS development software allow car dealers to grow their revenues more easily and across different locations. Variable $x_{a}$ accounts for APPS innovation in our econometric model.

Firms decide on the scale of production $x_{y i}$, measured as the logarithm of turnover in thousands of euros, together with the adoption of APPS development software, $x_{a i}$, and HR development software, $x_{h i}$. The choice of these strategies together with other unobserved ones determines the level of profits for each firm $\pi_{i}$. We measure profits as turnover minus remuneration and materials cost (again in thousands of euros). Is there any evidence that the scale varies with the set of innovations adopted, i.e. that it is really an endogenous variable? Table 2 breaks down the distribution of innovation profiles across competition regimes. For each innovation profile we also report the average scale and profits of the corresponding subsample of firms. Most dealers do not engage in any innovation strategy, but there is an overall change in innovation strategies after the liberalization of the European automobile distribution system. Dealers narrow the scope of their innovation profiles by further favoring HR over APPS innovations. Finally, substantially larger dealers are more likely to engage in joint adoption of innovations. Therefore, a model where the scale of production was treated as exogenous would be misspecified in this case.

To complete our descriptive analysis, Table 3 reports Kendall's $\tau$ coefficients of association among the different strategies of firms and between each strategy and profits before and after liberalization. These nonlinear correlation coefficients are useful to test for the existence of unconditional complementarity, i.e., the outcome of a profit func-

\footnotetext{
${ }^{15}$ See 2007 report by Microfocus: "Tesco Creates a Common Operating Model for Quick Deployment," available at http://www.microfocus.com/000/Tescol_highres\_US\_V2\_tcm21-15509.pdf.

${ }^{16}$ See the 2005 report by Capgemini: "Cars Online 04/05: Driving Growth Through Collaboration," which is available at http://www.capgemini.com/m/en/tl/pdf_Cars_Online_04_05_Driving_Growth_Through_Collaboration.pdf.
} 
TABle 3-Association among Endogenous Variables

\begin{tabular}{llrrlll}
\hline \hline & \multicolumn{1}{c}{$x_{y}, x_{a}$} & $x_{y}, x_{h}$ & $x_{a}, x_{h}$ & $\pi, x_{y}$ & $\pi, x_{a}$ & $\pi, x_{h}$ \\
\cline { 2 - 6 } All Periods & $0.112^{* * *}$ & 0.019 & -0.036 & $0.789^{* * *}$ & $0.121^{* * *}$ & 0.028 \\
Pre-Expiry & $0.131^{* * *}$ & 0.022 & -0.052 & $0.789^{* * *}$ & $0.138^{* * *}$ & 0.030 \\
Post-Expiry & 0.090 & -0.007 & 0.005 & $0.785^{* * *}$ & $0.106^{*}$ & 0.005 \\
\hline
\end{tabular}

Kendall's $\tau$ association coefficients. Significance levels are indicated with ${ }^{*}$ for p-values less than 0.1 ; ${ }^{* *}$ for less than $\mathbf{0 . 0 5}$; and ${ }^{* * *}$ for less than 0.01 .

tion being pairwise supermodular in each possible pair of strategies while ignoring all other differences among firms. ${ }^{17}$ The coefficients show that larger firms are more likely to adopt APPS software, especially before liberalization. Along the lines of the relations already discussed in Table 2, APPS and HR software appear to be substitutes, i.e., the profit function would be submodular in these two arguments, although this negative association is not significant. Note that competition strengthens or weakens the complementarity/substitutability relations but never reverses the sign. Note further the strong positive correlation between scale and profits, which also include the outcome of other non-observable dealers' strategies.

\section{Causality}

In this paper we argue that the change in regulation of vertical restraints in the European automobile industry increases competition among dealers thus triggering a change in behavior that affects scale and innovation decisions among other strategies. We believe that this is a reasonable explanation consistent with the available data for other industries and countries. We thus first compared the dynamics of software adoption in similar industries in France that did not experience a regulatory change. Our limited data suggest that the year-by-year change in APPS adoption was increasing in other retail industries while decreasing in SIC code 5511, and that post-expiry of 1475/95, HR adoption increased in SIC code 5511 while it decreased in other retail industries. Thus, it would appear unlikely that changes in prices or profitability arising from sources other than the expiry of the EU regulation led to such diverging outcomes in technologically similar industries.

An alternative that avoids the effects of likely heterogeneity across industries regarding the use of different strategies is to pool information from another country where the E.U. regulation change has no effect. In an analysis similar to the one presented in Table 5 below, we pool French and Norwegian data (Norway does not belong to the E.U.) and find that sales in Norway in 2003-2004 (which defines the liberalization dummy in our application) were not much different from those in 2000-2002. French dealers

\footnotetext{
${ }^{17}$ Ashish Arora and Alfonso Gambardella (1990) first computed similar correlations to test for the existence of complementarity although the theoretical foundation of this test is due to Bengt Holmström and Paul R. Milgrom (1994). Eugenio J. Miravete and José C. Pernías (2010) show that such a simple correlation analysis cannot capture the effect of complementarity when decision variables are, as in the present case, dichotomous.
} 
sold, on average, fewer vehicles than their Norwegian counterparts. However, the most interesting result is the positive and highly significant effect of the dummy differentiating the effect of liberalization in France and Norway. Its positive estimate indicates that the output of French dealers increased after the removal of territorial exclusivity. Thus, including Norway as a control group provides some reassurance that there is indeed a structural change that follows the liberalization of the E.U. automobile distribution system. $^{18}$

\section{Econometric Model}

Our estimation approach fully implements the framework put forward by Susan C. Athey and Scott Stern (1998). This is the first time the "adoption approach" (based on innovation profiles of firms) and the "productivity approach" (based on the actual return to each strategy) are integrated in a single estimation procedure. The specification of a flexible, yet general, profit function lets us disentangle the effect of complementarity from correlations among unobserved returns to each strategy. ${ }^{19}$

The econometric model builds on Miravete and Pernías (2006) with two important points of departure. First, we do not explicitly distinguish whether different software products are demand enhancing or cost reducing innovations. Thus, the profit function becomes a black box that captures the total effect of all strategies employed by the firm, therefore reducing the need for ad-hoc exclusion restrictions that help identify independent shifts of demand or marginal cost functions. ${ }^{20}$ Second, the estimation makes use of the information on profits associated with the scale decision and innovation profile of each firm, therefore avoiding the need to normalize several parameters of the profit function. Accounting profits are not normally employed in empirical studies. We include turnover in the same spirit as the productivity approach evaluates the effectiveness of innovations by metrics such as output, exports, or labor productivity. Interestingly, accounting profits are an aggregate indicator of overall returns, including those of other unobserved strategies.

Software adoption indicators are dichotomous variables, something that adds to the complexity of the estimation, but accurately reflects the discrete nature of innovation adoption decisions. In addition, to deal with the important effects of unobserved returns to each strategy we assume them to be jointly normally distributed so that we can evaluate how the unobserved heterogeneity associated with implementing each strategy, - - i.e., unobserved, strategy specific returns - affects the profitability of the rest of the strategies. As Athey and Stern $(1998, \S 4.2)$ point out, allowing for an unrestricted variance-covariance matrix of the distribution of these unobserved returns "provides a

\footnotetext{
${ }^{18}$ Results are available from the authors upon request.

${ }^{19}$ Susan C. Athey and Scott Stern (2002) and Casey Ichniowski, Kathryn Shaw and Giovanna Prennushi (1997) are examples of the productivity approach while Miravete and Pernías (2006) is an example of the adoption approach. Bruno Cassiman and Reinhilde Veugelers (2006) apply both approaches, although not jointly but separately, to study potential complementarities between internal R\&D and external knowledge acquisition.

${ }^{20}$ It is doubtful that we could build a meaningful economic model where we could credibly argue that, for instance, APPS software innovation only shifts demand while HR software innovation only shifts marginal costs and further, for instance, that population density could be excluded from the demand equation while per capita GDP could be excluded from the marginal cost equation.
} 
parsimonious specification that still accommodates the main alternative hypothesis regarding complementarity among strategies and the role of unobserved heterogeneity." Thus, the identification of the model relies on the flexible functional form of the profit function and an unrestricted multivariate normal distribution of the structural errors of the model associated to the unobserved returns to each strategy of firms.

\section{A. The Profit Function}

We write the profit function of firm $i$ as ${ }^{21}$

$$
\begin{aligned}
\pi_{i}\left(x_{a i}, x_{h i}, x_{y i}\right)= & \theta_{\pi}+\epsilon_{\pi i}+\left(\theta_{a}+\epsilon_{a i}\right) x_{a i}+ \\
& \left(\theta_{h}+\epsilon_{h i}\right) x_{h i}+\left(\theta_{y}+\epsilon_{y i}\right) x_{y i}+ \\
& \delta_{a h} x_{a i} x_{h i}+\delta_{a y} x_{a i} x_{y i}+\delta_{h y} x_{h i} x_{y i}-(\gamma / 2) x_{y i}^{2}
\end{aligned}
$$

This general profit function imposes very little structure on the underlying production technology. It is quadratic in scale $x_{y i}$ and the adoption of software innovations is represented by two dichotomous variables, $x_{a i}$ and $x_{h i}$. It also includes pairwise interaction terms among all these strategies - parameters $\delta_{a h}, \delta_{a y}$, and $\delta_{h y}$ - whose estimated signs determine whether the profit function is supermodular or submodular in each pair of strategies. No assumptions are made about these potentially complementarity relations and our estimates will determine them regardless of whether the strategies are continuous, such as scale, or discrete, as in the case of innovations. We envision firm $i$ choosing its scale and innovation profile to maximize the profit function $\pi_{i}\left(x_{a i}, x_{h i}, x_{y i}\right)$. For the solution of this problem to be well defined we only need to assume that equation (1) is concave on the $x_{y i}$ dimension.

An important goal of the econometric estimation is to determine whether the associations in Table 3 are due to the existence of complementarities, i.e., estimates of $\delta_{a h}$, $\delta_{a y}$, or $\delta_{h y}$ that are significantly different from zero, or alternatively, due to the existence of other unobserved elements of firms' environments for which we do not have information. The existence of returns $\left(\epsilon_{a i}, \epsilon_{h i}, \epsilon_{y i}, \epsilon_{\pi i}\right)$ that are observed by firms but not by econometricians explains why firms with identical observable characteristics $\left(\theta_{a}, \theta_{h}, \theta_{y}, \theta_{\pi}\right)$ may end up choosing different strategies $\left(x_{a i}, x_{h i}, x_{y i}\right)$ and reaching different profit levels, $\pi_{i}$. For this reason the return to each strategy, i.e., its direct impact on profits, includes an observed component $-\theta_{a}, \theta_{h}$, and $\theta_{y}-$ and an unobserved one $-\epsilon_{a i}, \epsilon_{h i}$, and $\epsilon_{y i}$ - to control for the possibility that unobservable features of firm organization and/or the innovation and production decisions lead to co-movements among strategies which is only the result of not having more detailed information about the relevant environment in which firms operate. ${ }^{22}$ Note also that there is an independent profit

\footnotetext{
${ }^{21}$ It could be questioned whether our model is appropriate, i.e., whether a dealer or a dealer group actually chooses these strategies or if manufacturers make these choices for them. Manufacturers do not have any legal competence on deciding over sales or any other decisions of dealers. Moreover in 2004, there were only 388 manufacturer owned dealers out of 12,774 total dealers.

${ }^{22}$ These could be, for example, the flatness of the firm's hierarchy of Timothy F. Bresnahan, Erik Brynjolfsson and
} 
contribution from other non-observable strategies of the firm. This separate term for the profit contribution of all other strategy variables combined comprises an observed component, $\theta_{\pi}$ and an unobserved one, $\epsilon_{\pi i}$. They will be allowed to be freely correlated with the rest of unobserved returns of the model. ${ }^{23}$

The rest of this section discusses how the available information suffices to identify the key parameters of the model given the profit function (1) and a flexible distribution of the structural errors $\left(\epsilon_{a i}, \epsilon_{h i}, \epsilon_{y i}, \epsilon_{\pi i}\right)$. We show that for any vector $\left(\epsilon_{a i}, \epsilon_{h i}, \epsilon_{y i}, \epsilon_{\pi i}\right)$ of unobserved returns to demand enhancing and cost reducing innovations, unobserved returns to production scale, and the profit contribution of the rest of strategies, respectively, there is a unique vector $\left(x_{a i}, x_{h i}, x_{y i}, \pi_{i}\right)$ of optimal strategies and total profits that rationalizes the observed scale and innovation profile as profit maximizing behavior. We estimate an equilibrium model in the sense that we derive the restrictions on the unobservables implied by profit maximizing behavior to obtain the parameter estimates from the sample combinations of strategy profiles.

\section{B. Scale choice}

We first analyze the optimal scale choice. The first order condition for profit maximization is

$$
\frac{\partial \pi_{i}}{\partial x_{y i}}=\theta_{y}+\epsilon_{y i}+\delta_{a y} x_{a i}+\delta_{h y} x_{h i}-\gamma x_{y i}=0 .
$$

From here, the optimal scale choice contingent on the innovation profile of the firm is

$$
x_{y i}^{\star}\left(x_{a i}, x_{h i}\right)=\gamma^{-1}\left(\theta_{y}+\epsilon_{y i}+\delta_{a y} x_{a i}+\delta_{h y} x_{h i}\right) .
$$

The sufficient condition for profit maximization requires that $\gamma>0$, i.e., that profit function (1) is concave in $x_{y i}$. Next, we write $\pi_{i}^{\star}\left(x_{a i}, x_{h i}\right)=\pi_{i}\left(x_{a i}, x_{h i}, x_{y i}^{\star}\left(x_{a i}, x_{h i}\right)\right)$ and after substituting the optimal scale (3) into the profit function (1) we get

$$
\pi_{i}^{\star}\left(x_{a i}, x_{h i}\right)=\kappa_{\pi i}+\epsilon_{\pi i}+\left(\kappa_{a i}+\epsilon_{a i}\right) x_{a i}+\left(\kappa_{h i}+\epsilon_{h i}\right) x_{h i}+\delta x_{a i} x_{h i},
$$

where

$$
\begin{aligned}
\kappa_{\pi i} & =\theta_{\pi}+\left(\theta_{y}+\epsilon_{y i}\right)^{2} /(2 \gamma), \\
\kappa_{a i} & =\theta_{a}+\delta_{a y}\left[\delta_{a y} / 2+\left(\theta_{y}+\epsilon_{y i}\right)\right] / \gamma,
\end{aligned}
$$

Lorin M. Hitt (2002) or certain management capabilities to realize the potential profits of combining firm strategies.

${ }^{23}$ The stochastic structure of equation (1) is what Athey and Stern (1998) label "Random Practice Model," i.e., a profit function where each strategy incorporates an unobservable return which, despite being freely correlated to each other, they do not depend on other strategies of the firm. Thus, parameters affecting the cross-products of strategies $\left(\delta_{a h}, \delta_{a y}, \delta_{h y}\right)$, are non-stochastic. Alternatively, the "Random System Model" incorporates a common unobserved return to each combination of strategies. This latter specification is far more demanding as it requires sufficient realizations of all potential combinations of innovation profiles for each combination of value of the explanatory variables included in $\left(\delta_{a h}, \delta_{a y}, \delta_{h y}\right)$, something that goes beyond the limits of our data. 


$$
\begin{aligned}
\kappa_{h i} & =\theta_{h}+\delta_{h y}\left[\delta_{h y} / 2+\left(\theta_{y}+\epsilon_{y i}\right)\right] / \gamma, \\
\delta & =\delta_{a h}+\delta_{a y} \delta_{h y} / \gamma .
\end{aligned}
$$

\section{Innovation profile choice}

Once we have obtained the optimal scale as a function of innovations in equation (3), we need to determine how the observed innovation profile identifies the innovation related parameters of the model. Firm $i$ chooses its innovation profile to maximize profits. Firms can adopt APPS software, in which case $x_{a i}=1$. Similarly, when they adopt HR software, $x_{h i}=1$. Therefore, firm $i$ chooses one of four innovation profiles: (i) adoption of APPS innovation only, $x_{a i}=1, x_{h i}=0$; (ii) adoption of HR innovation only, $x_{a i}=0, x_{h i}=1$; (iii) adoption of both innovations, $x_{a i}=1, x_{h i}=1$; and (iv) adoption of no innovation at all, $x_{a i}=0, x_{h i}=0$. From equation (4), we can then write the profits for each of the four innovation profiles as follows:

$$
\begin{aligned}
& \pi^{\star}(1,1)=\kappa_{\pi i}+\kappa_{a i}+\kappa_{h i}+\delta+\epsilon_{\pi i}+\epsilon_{a i}+\epsilon_{h i}, \\
& \pi^{\star}(1,0)=\kappa_{\pi i}+\kappa_{a i}+\epsilon_{\pi i}+\epsilon_{a i}, \\
& \pi^{\star}(0,1)=\kappa_{\pi i}+\kappa_{h i}+\epsilon_{\pi i}+\epsilon_{h i}, \\
& \pi^{\star}(0,0)=\kappa_{\pi i}+\epsilon_{\pi i},
\end{aligned}
$$

which provide us with the restrictions on unobservables associated to each strategy profile. Thus, if a firm engages in both innovation activities we have:

$$
\begin{aligned}
& \pi^{\star}(1,1)>\pi^{\star}(1,0), \\
& \pi^{\star}(1,1)>\pi^{\star}(0,1), \\
& \pi^{\star}(1,1)>\pi^{\star}(0,0) .
\end{aligned}
$$

These conditions imply that observing firm $i$ adopting both innovations correspond to the following restrictions on the unobserved returns to product and process innovation $\left(\epsilon_{a i}, \epsilon_{h i}\right)$ :

$$
\begin{aligned}
\epsilon_{a i} & >-\kappa_{a i}-\delta, \\
\epsilon_{h i} & >-\kappa_{h i}-\delta, \\
\epsilon_{a i}+\epsilon_{h i} & >-\kappa_{a i}-\kappa_{h i}-\delta .
\end{aligned}
$$

We can repeat this analysis for all other innovation profiles. For simplicity, we apply the following definitions:

$$
\begin{aligned}
\epsilon_{s i} & =\epsilon_{h i}+s_{i} \epsilon_{a i}, \\
q_{a i} & =2 x_{a i}-1, \\
q_{h i} & =2 x_{h i}-1, \\
s_{i} & =q_{a i} q_{h i} .
\end{aligned}
$$


The following notation generalizes inequality conditions (8a)-(8c). Let $S_{i}\left(x_{a i}, x_{h i}\right)$ denote the set of realizations of $\left(\epsilon_{a i}, \epsilon_{h i}\right)$ for any given value of $\epsilon_{y i}$ such that they lead to the observed choices of product and process innovation, $\left(x_{a i}, x_{h i}\right)$. The set $S_{i}\left(x_{a i}, x_{h i}\right)$ is defined from the following three inequalities: ${ }^{24}$

$$
\begin{aligned}
& q_{a i} \epsilon_{a i}>-q_{a i}\left(\kappa_{a i}+\delta x_{h i}\right), \\
& q_{h i} \epsilon_{h i}>-q_{h i}\left(\kappa_{h i}+\delta x_{a i}\right), \\
& q_{h i} \epsilon_{s i}>-q_{h i}\left[\kappa_{h i}+\delta / 2+s_{i}\left(\kappa_{a i}+\delta / 2\right)\right] .
\end{aligned}
$$

Figure 1 shows the shape of the $S_{i}\left(x_{a i}, x_{h i}\right)$ regions for positive and negative values of $\delta$. Notice that these disjoint regions are defined by the observed and unobserved returns associated to scale and innovations. Neither $\epsilon_{\pi i}$ nor $\theta_{\pi}$ appear in conditions (13a)(13c). However, both $\epsilon_{y i}$ and $\theta_{y}$ define these integration regions through $\kappa_{a i}$ and $\kappa_{h i}$. Further, as long as the profit function is increasing and concave in $x_{y i}$, i.e., $\gamma>0$ the model is coherent in the sense that any given realization of the errors $\left(\epsilon_{a i}, \epsilon_{h i}, \epsilon_{y i}, \epsilon_{\pi i}\right)$ is associated unambiguously with a firm with given scale, innovation profile, and profit level. ${ }^{25}$

The intuition of this coherence result goes as follows. First, observe that each realization of $\left(\epsilon_{y i}, \epsilon_{a i}, \epsilon_{h i}\right)$ is uniquely associated with a particular innovation profile $\left(x_{a i}, x_{h i}\right)$ through conditions (13a)-(13c). Equation (3) then uniquely determines the scale $x_{y i}$. Finally, for any given realization of $\epsilon_{\pi} i$, the observable direct profit contribution of the rest of the strategies $\theta_{\pi}$ is determined by equation (1) as a residual from observable profits after the contributions of scale and innovations are accounted for. Thus, for a given realization of $\left(\epsilon_{a i}, \epsilon_{h i}, \epsilon_{y i}, \epsilon_{\pi i}\right)$ there is a unique corresponding vector $\left(x_{a i}, x_{h i}, x_{y i}, \pi_{i}\right)$ that satisfies the profit maximization conditions for the parameters $\left(\theta_{a}, \theta_{h}, \theta_{y}, \theta_{\pi}\right){ }^{26}$

To estimate the model we assume that $\epsilon_{i}=\left(\epsilon_{a i}, \epsilon_{h i}, \epsilon_{y i}, \epsilon_{\pi i}\right)^{\prime}$ follows a tetravariate normal distribution with zero means and standard deviations $\left(\sigma_{a}, \sigma_{h}, \sigma_{y}, \sigma_{\pi}\right)^{\prime}$. The joint density of $\boldsymbol{\epsilon}_{i}$ can be written as

$$
f\left(\epsilon_{a i}, \epsilon_{h i}, \epsilon_{y i}, \epsilon_{\pi i}\right)=\left(\sigma_{a} \sigma_{h} \sigma_{y} \sigma_{\pi}\right)^{-1} \phi_{4}\left(\frac{\epsilon_{a i}}{\sigma_{a}}, \frac{\epsilon_{h i}}{\sigma_{h}}, \frac{\epsilon_{y i}}{\sigma_{y}}, \frac{\epsilon_{\pi i}}{\sigma_{\pi}} ; \boldsymbol{R}\right),
$$

where $\phi_{4}(\cdot ; \boldsymbol{R})$ denotes the probability density function of a four-variate normal distri-

\footnotetext{
${ }^{24}$ Notice that the third restriction (8c) is non-binding when $\delta \leq 0$, as can be checked by adding the first two conditions (8a) and ( $8 \mathrm{~b})$. Similarly, the last of these conditions is non-binding if $s_{i} \delta \leq 0$.

${ }^{25}$ As Figure 1 shows, the areas of integration corresponding to each innovation profile are not rectangular unless $\delta=0$. This situation is common in the entry literature. Both Steven T. Berry (1992) and Michael J. Mazzeo (2002) encounter non-rectangular integrations areas similar to those of Figure 1. They resort to simulation to estimate their models. Miravete and Pernías (2006) make use of a Gauss-Legendre quadrature to evaluate the probabilities of each innovation profile. Web Appendix A shows that a simple change of basis allows us to evaluate Prob $\left[\left(\epsilon_{a i}, \epsilon_{h i}\right) \in S_{i}\left(x_{a i}, x_{h i}\right)\right]$ as the sum of two bivariate normal integrals over two disjoint regions. If we were to consider numerous discrete strategies this method would become impractical and we would also have to resort to simulations to estimate our model.

${ }^{26}$ Miravete and Pernías $(2010, \S 2.3)$ discuss in detail the coherence of econometric models aimed at testing for the existence of complementarities among dichotomous (innovation) strategies in the presence of unobservable heterogeneity that influences the return to different strategies of firms.
} 
(a) $\delta>0$

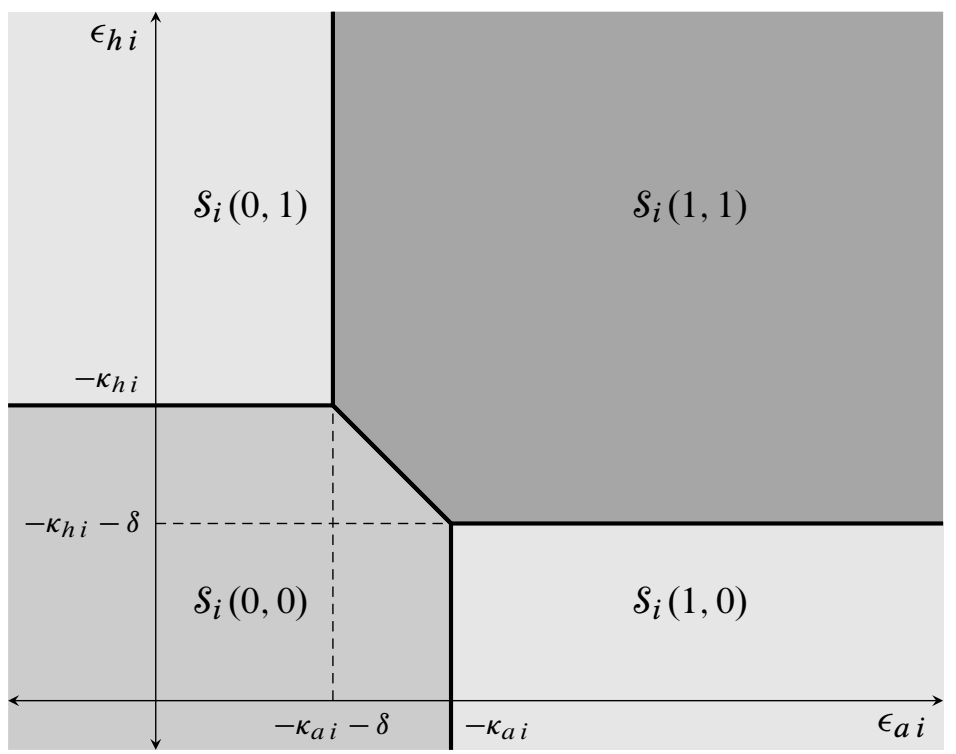

(b) $\delta<0$

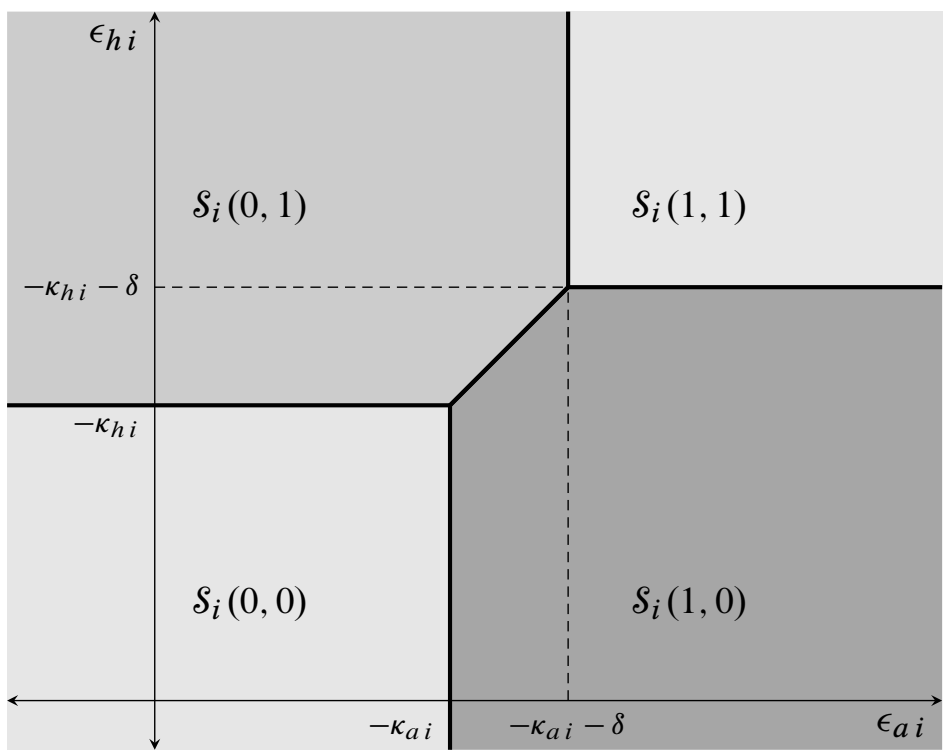

FIGURE 1. INNOVATION PROFILE DEFINING REGIONS 
bution with mean vector $\mathbf{0}$, unit variances, and correlation matrix

$$
\boldsymbol{R}=\left(\begin{array}{cccc}
1 & \rho_{a h} & \rho_{a y} & \rho_{a \pi} \\
\rho_{a h} & 1 & \rho_{h y} & \rho_{h \pi} \\
\rho_{a y} & \rho_{h y} & 1 & \rho_{y \pi} \\
\rho_{a \pi} & \rho_{h \pi} & \rho_{y \pi} & 1
\end{array}\right)
$$

Equation (3) and conditions (13a)-(13c), can be used to test for the existence and direction of complementarities, as in Miravete and Pernías (2006). Making use of accounting profits further enables us to estimate $\gamma$, all $\pi$-indexed parameters of the profit function (1), and those of the multivariate distribution of unobservables. Working along these lines, we construct the likelihood function of this model under the assumption that $\left(\epsilon_{a i}, \epsilon_{h i}, \epsilon_{y i}, \epsilon_{\pi i}\right)$ follows this unrestricted multivariate normal distribution in Web Appendix A. The model is empirically identified as our data includes all innovation profiles in different proportions before and after the removal of the exclusive territory restraints as documented in Table 2 and Table $3 .^{27}$

\section{Empirical Results and Interpretation}

We now evaluate the effect of different firm and market characteristics on the direct returns to each strategy. In doing so, we consider different specifications of the model allowing for alternative combinations of complementarities and unobserved heterogeneity. We specify the vector of parameters $\left(\theta_{a}, \theta_{h}, \theta_{y}, \theta_{\pi}\right)$ as linear functions of observable variables. ${ }^{28}$

Table 4 presents the sample distribution of all regressors. However, not all of them are included in the final specification of the model of Table 6. Ideally we would like to include market indicators as regressors in the four observable returns $\left(\theta_{a}, \theta_{h}, \theta_{y}, \theta_{\pi}\right)$. However, this would leave us without sufficient observations given the large number of dèpartements and the many parameters of our nonlinear model. Our preferred model therefore includes the following regressors:

1) LIB is a dummy variable identifying all observations from the years 2003 and 2004, i.e., after the European automobile distribution system was liberalized. This variable

\footnotetext{
${ }^{27}$ Proving identification in general in nonlinear models like the present one is a difficult task. Closely related to ours, Bryan W. Brown (1983) makes use of the concept of observational equivalence to discuss the identification of a model that is nonlinear in parameters only. Roger Bowden (1973) focuses on the identification of the distribution of the random components by making use of Kullback's information integral for any nonlinear model. Thomas J. Rothenberg (1971) shows that an econometric model such as the one defined by the flexible profit function (1) together with the unrestricted multivariate normal distribution of unobserved returns $\left(\epsilon_{a i}, \epsilon_{h i}, \epsilon_{y i}, \epsilon_{\pi i}\right)$ is identified as long as the information matrix of the likelihood function is nonsingular. In the simplest case of Table 5 , this implies confirming that the determinant of an $(18 \times 18)$ matrix is non-zero at the estimated values of $\left(\theta_{a}, \theta_{h}, \theta_{y}, \theta_{\pi}\right)$ for any possible realization of $\left(\epsilon_{a i}, \epsilon_{h i}, \epsilon_{y i}, \epsilon_{\pi i}\right)$. As this is impractical, we checked for the robustness of our estimates by using a wide array of initial values. This is the standard procedure to check for identification and uniqueness in the estimation of nonlinear models. Our estimates always converged to the same values.

${ }^{28}$ Miravete and Pernías (2006) need exclusion restrictions to estimate their model because they consider one demandenhancing and one cost reducing innovation. Thus, they need to isolate demand shifts independently from shifts in marginal costs. Both APPS and HR software innovations embody features of demand enhancing and cost reducing innovations. Therefore, at least in the framework of the present application, it makes little sense to define arbitrary exclusion restrictions.
} 
TABLE 4-SAMPLE Distributions OF EXOGENOUS VARIABLES

\begin{tabular}{|c|c|c|c|c|c|c|}
\hline & \multicolumn{2}{|c|}{ All periods } & \multicolumn{2}{|c|}{ Pre-Expiry } & \multicolumn{2}{|c|}{ Post-Expiry } \\
\hline & Mean & S.D. & Mean & S.D. & Mean & S.D. \\
\hline $\ln (G D P p c)$ & 3.195 & 0.320 & 3.171 & 0.325 & 3.240 & 0.305 \\
\hline $\ln ($ Density $)$ & 5.541 & 1.693 & 5.530 & 1.705 & 5.563 & 1.673 \\
\hline $\ln$ (Population) & 13.596 & 0.674 & 13.583 & 0.672 & 13.622 & 0.679 \\
\hline Urban & 0.106 & 0.309 & 0.093 & 0.291 & 0.132 & 0.340 \\
\hline Near & 0.199 & 0.399 & 0.193 & 0.395 & 0.210 & 0.408 \\
\hline Paris & 0.041 & 0.198 & 0.040 & 0.197 & 0.041 & 0.199 \\
\hline$N$ & \multicolumn{2}{|c|}{639} & \multicolumn{2}{|c|}{420} & \multicolumn{2}{|c|}{219} \\
\hline \multicolumn{7}{|c|}{$\begin{array}{l}\text { Means and standard deviations of exogenous variables by competition regime. The first } \\
\text { three variables are measured in logarithms. Gross domestic product per capita is mea- } \\
\text { sured in thousands of euros; population density in people per square kilometer; and popu- } \\
\text { lation in number of inhabitants of each market. The remaining variables are dummies. } N \\
\text { denotes the number of dealers in each sample. }\end{array}$} \\
\hline
\end{tabular}

is intended to capture the effects of this regime change and the associated increase in competitive pressure on all endogenous variables of the model.

2) $\ln (G D P p c)$ is the logarithm of the gross domestic product per capita in each dèpartement measured in thousands of euros. We use this to account for differences in the purchasing power of potential customers across markets that may relate to the price elasticity of demand in each local market.

3) $\ln$ (Density) is the logarithm of the population density of each market measured as the number of inhabitants per square kilometer. Density may have several possible effects. First, it is related to the cost of storage and display; in densely populated markets rental space is more expensive. If this effect dominates, density should affect scale negatively. Second, we can think of dense markets as being more competitive since consumers can compare prices, products, and quality of services more easily and thus switch from one dealer to another. Chad Syverson (2004) argues that the pro-competitive effect of density is to foster efficiency (innovation adoption in our case) and allow larger scales for a larger number of firms, since smaller and less efficient ones do not survive in such demanding environments.

4) $\ln ($ Population $)$ is the logarithm of population in each dèpartement. Population accounts for market size, which may play a significant role if dealers face important fixed cost of entry.

5) Paris is a dummy variable to denote whether dealers are located in the Paris area, which may face particularly different distribution costs, sophisticated consumers, or access to know-how that affects the adoption of innovations. 


\section{A. The Effect of Competitive Pressure on Adoption and Scale}

Table 5 evaluates the effect of liberalization in the European automobile distribution system ignoring the effect of other potential covariates. Table 6 presents the estimates of four different vectors of $\left(\theta_{a}, \theta_{h}, \theta_{y}, \theta_{\pi}\right)$ of the general model described in Section II. We find that although the inclusion of market characteristics improves the estimation, the effect of liberalization $(L I B)$ retains its sign whenever it is significant and estimates of complementarity effects, $\left(\delta_{a h}, \delta_{a y}, \delta_{h y}\right)$ are robust to the inclusion of additional regressors. The same holds for the correlation among the unobservable returns to each strategy, in particular for the results of Model IV. Likelihood ratio tests similar to those at the top of Table 7 always rejects the more restrictive model in favor of the more general one, leaving Model IV as our preferred specification. That is, both unobservable heterogeneity and complementarities matter in explaining simultaneous scale and product and process innovation decisions. Consequently, we focus on the parameter estimates of Model IV. ${ }^{29}$

We start by analyzing the effect of competitive pressure. The liberalization of the European distribution system has significant direct effects on the returns to scale and HR software innovation. The positive sign of the estimate of $L I B$ on scale captures the effect of increased competition after the removal of the exclusive territory restraint. As the potential market expands, surviving dealerships increase the scale of their operations. This result confirms the unconditional increase in scale after 2002 documented in the third line of Table 1. In addition, our model allows for synergies among the returns of different strategies. A larger scale of production increases the profitability of adopting APPS software since these two strategies are complements, i.e., $\delta_{a y}>0$. Further, the two types of software are substitutes as $\delta_{a h}<0$.

Competition increases the returns to adopting HR software independent of the scale of dealerships. The effect of liberalization on APPS software adoption is also positive but only indirectly, through an increase in the optimal scale of dealerships and the complementary relationship between scale and APPS software. However, it is likely that the overall effect of competition on the return to adopt APPS software is much larger and negative as the synergy effect between APPS and HR software innovation is negative and larger (in absolute value) than any other effect. Therefore, APPS and HR adoptions are substitutes and dealers will specialize in adopting one of the two softwares as competitive pressure increases, a result consistent with the specialization hypothesis of Cohen and Klepper (1996). An interpretation consistent with this hypothesis is that perhaps developing a dealer website (APPS) can be easily imitated. Thus, returns to the adoption of APPS software are less appropriable than adopting HR software to make personnel management more efficient; something that might be less portable to other dealerships.

Other regressors also have significant effects on the different strategies of the firms as shown in Table 6. The returns to scale and other non-observable strategies are higher in

\footnotetext{
${ }^{29}$ Since some dealerships appear several times in our data while others appear only once and we pool all the data to estimate our nonlinear model, we make use of cluster-robust standard errors to obtain the correct inference. They are not only heteroskedastic-consistent, but also take into account the clustered nature of the data when repeated observations of the same firm are present. See Jeffrey M. Wooldridge (2002, §13.8.2).
} 
Table 5-Estimates: French Automobile Retailing (without Market Controls)

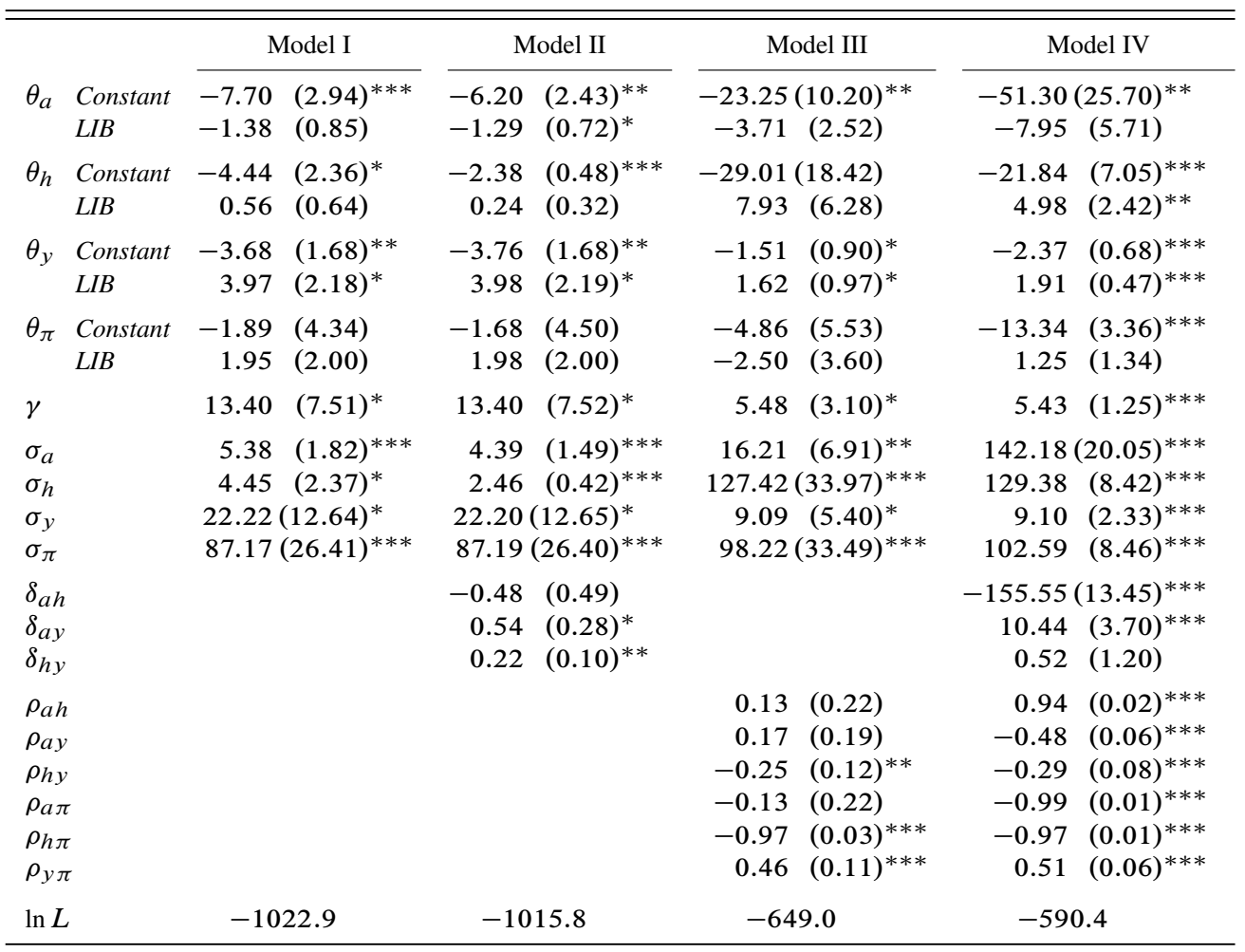

Maximum likelihood estimates. Cluster-robust standard errors are reported in between parentheses. Significance levels are indicated with ${ }^{*}$ for p-values less than $0.1{ }^{* *}$ for less than 0.05 ; and ${ }^{* * *}$ for less than 0.01 . There is a total of 639 observations.

larger and more affluent markets. Conversely, the returns to both software innovations are higher in markets with lower income per capita and less population (APPS only). These surprising negative effects are not necessarily the total effect of market size and income on the returns to innovate since the model includes nonlinear interactions: $\ln (G D P p c)$ and $\ln$ (Population) also favors larger-scale dealerships which, in turn, favor the adoption of APPS software, which in turn is a substitute of HR software. We will analyze the interactions of these nonlinearities when discussing the results of the simulations of the model later in Table 9.

An exogenous change in regulation, $L I B$, is not the only way to measure the effects of increased competitive pressure. Competitiveness may also vary across markets due to other factors. Syverson (2004) suggests using population density to control for these market-specific differences in competitiveness. The idea is that more densely populated areas require more firms to serve it, thus enabling consumers to switch suppliers, leading to a higher degree of product substitution. ${ }^{30}$ We include this variable as a regressor

${ }^{30}$ According to Vives $(2008, \S 1)$, this is a useful measure of competitive pressure both with and without entry. Notice 
TABle 6-Estimates: French Automobile Retailing

\begin{tabular}{|c|c|c|c|c|c|c|c|}
\hline \multirow[b]{2}{*}{$\theta_{a}$ Constant } & \multicolumn{2}{|c|}{ Model I } & \multicolumn{2}{|c|}{ Model II } & \multicolumn{2}{|c|}{ Model III } & \multirow{2}{*}{$\frac{\text { Model IV }}{-55.96(12.69)^{* * *}}$} \\
\hline & -3.33 & $(0.80)^{* * *}$ & -3.05 & $(0.91)^{* * *}$ & -6.55 & $(77.55)$ & \\
\hline$L I B$ & -0.66 & $(0.40)^{*}$ & -0.67 & $(0.39)^{*}$ & -1.33 & $(15.57)$ & $-0.72 \quad(5.37)$ \\
\hline $\ln (G D P p c)$ & 1.90 & $(1.46)$ & 1.61 & $(1.42)$ & 4.18 & $(49.25)$ & $-57.06(22.48)^{* *}$ \\
\hline $\ln ($ Density $)$ & -0.10 & $(0.23)$ & -0.02 & $(0.23)$ & -0.17 & $(2.59)$ & $11.49(3.85)^{* * *}$ \\
\hline $\ln ($ Population $)$ & -0.46 & $(0.71)$ & -0.61 & $(0.71)$ & -1.12 & (13.54) & $-27.29(7.66)^{* * *}$ \\
\hline Paris & 0.05 & $(1.77)$ & -0.19 & $(1.57)$ & -0.79 & $(10.69)$ & $77.74(41.23)^{*}$ \\
\hline$\theta_{h}$ Constant & -2.48 & $(0.55)^{* * *}$ & -1.43 & $(0.20)^{* * *}$ & -37.75 & $(41.13)$ & $-26.11(3.82)^{* * *}$ \\
\hline$L I B$ & 0.37 & $(0.32)$ & 0.20 & $(0.18)$ & 16.23 & $(16.16)$ & $9.57(3.21)^{* * *}$ \\
\hline $\ln (G D P p c)$ & -1.15 & (1.27) & -0.87 & $(0.77)$ & -135.39 & $(186.67)$ & $-77.08(14.43)^{* * *}$ \\
\hline $\ln ($ Density $)$ & -0.18 & $(0.25)$ & -0.08 & $(0.15)$ & 13.05 & $(41.70)$ & $8.23(1.94)^{* * *}$ \\
\hline $\ln ($ Population $)$ & 0.99 & $(0.47)^{* *}$ & 0.54 & $(0.30)^{*}$ & -5.59 & $(71.77)$ & $-2.41 \quad(3.30)$ \\
\hline Paris & 0.97 & $(1.39)$ & 0.62 & $(0.83)$ & 106.36 & $(286.22)$ & $67.35(32.51)^{* *}$ \\
\hline$\theta_{y}$ Constant & -3.33 & $(1.57)^{* *}$ & -3.37 & $(1.57)^{* *}$ & -1.42 & $(2.03)$ & $-2.19(0.54)^{* * *}$ \\
\hline$L I B$ & 2.75 & $(1.64)^{*}$ & 2.76 & $(1.64)^{*}$ & 1.20 & $(0.78)$ & $1.53(0.50)^{* * *}$ \\
\hline $\ln (G D P p c)$ & 15.95 & $(13.50)$ & 15.91( & $(13.49)$ & 7.00 & $(7.23)$ & $5.46(2.98)^{*}$ \\
\hline $\ln ($ Density $)$ & -3.58 & $(3.21)$ & -3.57 & $(3.20)$ & -1.55 & (1.53) & $-1.46(0.73)^{* *}$ \\
\hline $\ln ($ Population $)$ & 6.92 & (5.73) & 6.90 & (5.73) & 3.01 & $(2.68)$ & $3.16(1.17)^{* * *}$ \\
\hline Paris & 1.15 & $(10.42)$ & 1.14( & $(10.38)$ & 0.53 & $(12.83)$ & $0.47 \quad(3.26)$ \\
\hline$\theta_{\pi}$ Constant & 1.98 & (4.10) & 2.09 & $(4.12)$ & -1.80 & $(41.49)$ & $-9.84(1.56)^{* * *}$ \\
\hline$L I B$ & -3.57 & $(3.75)$ & -3.56 & (3.76) & -6.29 & $(13.66)$ & $-2.98(2.47)$ \\
\hline $\ln (G D P p c)$ & 76.58 & $(47.28)$ & 76.65 & $(47.36)$ & 61.71( & $(184.22)$ & $66.47(7.51)^{* * *}$ \\
\hline $\ln ($ Density $)$ & -13.44 & $(9.60)$ & -13.48 & $(9.61)$ & -6.82 & $(40.02)$ & $-8.69(1.06)^{* * *}$ \\
\hline $\ln ($ Population $)$ & 19.99 & $(11.83)^{*}$ & 20.08 & $(11.82)^{*}$ & 2.42 & $(62.55)$ & $8.72(1.50)^{* * *}$ \\
\hline Paris & -45.39 & $(31.33)$ & -45.22 & $(31.40)$ & -45.55 & $(253.19)$ & $-51.34(18.21)^{* * *}$ \\
\hline$\gamma$ & 13.49 & $(7.37)^{*}$ & 13.48 & $(7.36)^{*}$ & 5.98 & $(2.04)^{* * *}$ & $5.65(0.87)^{* * *}$ \\
\hline$\sigma_{a}$ & 2.29 & $(0.51)^{* * *}$ & 2.13 & $(0.62)^{* * *}$ & 4.56 & $(54.11)$ & $143.03(10.77)^{* * *}$ \\
\hline$\sigma_{h}$ & 2.38 & $(0.55)^{* * *}$ & 1.40 & $(0.18)^{* * *}$ & 128.29 & $(9.95)^{* * *}$ & $126.94(4.98)^{* * *}$ \\
\hline$\sigma_{y}$ & 21.96 & $(12.14)^{*}$ & 21.93( & $(12.13)^{*}$ & 9.75 & $(3.20)^{* * *}$ & $9.29(1.48)^{* * *}$ \\
\hline$\sigma_{\pi}$ & 85.87 & $(25.53)^{* * *}$ & 85.87 & $(25.52)^{* * *}$ & 97.71 & $(5.85)^{* * *}$ & $101.69(4.20)^{* * *}$ \\
\hline$\delta_{a h}$ & & & -0.21 & $(0.25)$ & & & $-159.56(6.60)^{* * *}$ \\
\hline$\delta_{a y}$ & & & 0.27 & $(0.13)^{* *}$ & & & $10.06(1.52)^{* * *}$ \\
\hline$\delta_{h y}$ & & & 0.13 & $(0.06)^{* *}$ & & & $0.06 \quad(0.92)$ \\
\hline$\rho_{a h}$ & & & & & 0.10 & $(0.75)$ & $0.95(0.01)^{* * *}$ \\
\hline$\rho_{a y}$ & & & & & 0.23 & $(0.34)$ & $-0.46(0.06)^{* * *}$ \\
\hline$\rho_{h y}$ & & & & & -0.23 & $(0.11)^{* *}$ & $-0.27(0.08)^{* * *}$ \\
\hline$\rho_{a \pi}$ & & & & & -0.03 & $(0.79)$ & $-0.99(0.00)^{* * *}$ \\
\hline$\rho_{h \pi}$ & & & & & -0.96 & $(0.02)^{* * *}$ & $-0.96(0.01)^{* * *}$ \\
\hline$\rho_{y \pi}$ & & & & & 0.48 & $(0.11)^{* * *}$ & $0.51(0.06)^{* * *}$ \\
\hline $\ln L$ & -99 & 1.8 & -985 & & -61 & 5.1 & -567.5 \\
\hline
\end{tabular}

Maximum likelihood estimates. Cluster-robust standard errors are reported in between parentheses. Significance levels are indicated with ${ }^{*}$ for $\mathrm{p}$-values less than $\mathbf{0 . 1}$; $^{* *}$ for less than 0.05 ; and ${ }^{* * *}$ for less than 0.01 . There is a total of 639 observations. 
in our estimation. Population density identifies competitive pressure through variations across markets and time. Indeed it has a positive effect on the returns to adopting both types of software but a negative effect on scale. Contrary to Syverson (2004) more dense markets feature smaller dealers. This suggests that the effect of costly storage dominates in an industry for which space scarcity in dense cities becomes critical. ${ }^{31}$ The lack of significance of the Paris dummy on scale supports this alternative interpretation. The Parisian market also behaves differently with respect to all innovation strategies, with very large returns for both APPS and HR software adoptions.

The unobserved returns associated to different strategies are significantly correlated with each other, therefore emphasizing the need to control for the existence of unobservable heterogeneity when estimating the determinants of potentially complementary firm strategies. Comparing Models II and IV, we can assess the effects of ignoring unobserved heterogeneity. The estimates of Model II ignore unobserved returns and offer a starkly different interpretation of the effect of liberalization. Following Model II, we would wrongly conclude that there are very small complementarities between scale and innovations and no complementarity at all between software decisions. Moreover, the increase in competitive pressure will not affect the scale of production or innovation activities. These results would be at odds with the unconditional correlations among strategies reported in Table 3.

We now evaluate the estimation bias of ignoring complementarities by comparing Model III and IV. The estimates of $\left(\rho_{a h}, \rho_{a y}, \rho_{h y}\right)$ in Model III are commonly used to evaluate complementarities following Arora and Gambardella (1990). It involves measuring the correlation of residuals after regressing the adoption of strategies on observable firm and market characteristics only. The estimates of Model III depict a situation where APPS software adoption would (wrongly) be independent of any other strategy and small firms would have an advantage in adopting HR software. The estimates of $\left(\delta_{a h}, \delta_{a y}, \delta_{h y}\right)$ in Model IV tell quite a different story, as discussed above. Further, ignoring complementarities also affects the significance of many other estimates. In particular, liberalization has no significant effect on any choice variable.

\section{B. Robustness of Estimates}

The estimates reported in Table 6 use most but not all information available to us. We experimented with different combinations of regressors to obtain the best fit of the model. Table 7 presents a collection of specification tests to provide support for our preferred specification. Indeed, all tests favor the specification of Model IV in Table 6 over any considered alternative.

The top section of Table 7 presents a set of likelihood ratio tests comparing the different specifications of the profit function under the null hypothesis that the first model (of each comparison) is the correct one. All paired tests favor the comparatively more

however that, given the nature of car distribution, population density may have a countervailing effect on competition due to the increasing costs of storage in urban areas.

${ }^{31}$ This intuition has been supported by interviews with industry experts who emphasized the space constraints car dealers face and the high proportion of real estate expenditures in overall expenditures. 
TABLE 7-Some SPECification TESTS

\begin{tabular}{lrrr}
\hline \hline & $\chi^{2}$ & d.f. & p-value \\
\hline LR tests for model comparisons & & & \\
Model I vs. Model IV & 848.58 & 9 & 0.000 \\
Model II vs. Model IV & 835.71 & 6 & 0.000 \\
Model III vs. Model IV & 95.28 & 3 & 0.000 \\
Model I vs. Model III & 753.30 & 6 & 0.000 \\
Model I vs. Model II & 12.87 & 3 & 0.005 \\
& & & \\
Wald test for joint significance & & & \\
All covariates & 1039.60 & 20 & 0.000 \\
LIB & 18.62 & 4 & 0.001 \\
ln(GDPpc) & 86.78 & 4 & 0.000 \\
ln(Density) & 100.55 & 4 & 0.000 \\
ln(Population) & 43.76 & 4 & 0.000 \\
Paris & 11.90 & 4 & 0.018 \\
Y2001 & & & \\
Y2002 & & & \\
Y2001, Y2002 & 0.87 & 4 & 0.929 \\
Urban & 3.01 & 4 & 0.555 \\
Near & 6.25 & 8 & 0.619 \\
Urban, Near & 2.39 & 4 & 0.664 \\
All & 1.08 & 4 & 0.898 \\
& 3.31 & 8 & 0.913 \\
& 9.72 & 16 & 0.881 \\
\hline
\end{tabular}

These test statistics are distributed, under the respective null hypothesis, as $\chi^{2}$ with degrees of freedom as indicated in the 'd.f.' column.

general over the more restrictive specification. Hence, Model IV, which allows for complementarities among strategies as well as correlated unobserved returns to each strategy, is our preferred specification.

The middle section of Table 7 evaluates whether the included regressors in our preferred specification are at all informative using a Wald test where the null hypothesis is that these regressors are not jointly significant. For instance, we test whether $\ln (G D P p c)$ can be excluded simultaneously in the specification of $\theta_{a}, \theta_{h}, \theta_{y}$, and $\theta_{\pi}$. The answer in all cases is negative.

The bottom section of Table 7 confirms that the remaining variables available to us do not improve the estimation. The logic for their potential inclusion (although the described effects are not significant) is the following. First, Urban indicates whether a large city (over 300,000 people) is located within the dèpartement defining the market. Cities may attract more sophisticated customers and skilled professionals. Thus, because of agglomeration effects, it may be easier in these areas to find the expertise to adopt innovations that improve service or allow firms to provide services more efficiently. Second, Near designates the dèpartements surrounding the dèpartement where a large city is located. This regressor is used to test whether this administrative division corresponds to a well defined market for the purposes of our study. Lastly, variables Y2001 and Y2002 are of particular interest. They are dummies that identify observations from the years 
2001 and 2002, just ahead of the liberalization of the European automobile distribution system. As discussed in Section I.A, the active regulation of this industry was known to expire in September of 2002. Thus, our definition of LIB might not capture the full effect of liberalization because dealers anticipated it. It is however well documented that while the overhaul of the old regulatory regime was known, the defining features of the new one were not decided until shortly before it was put into place. Estimates of $Y 2001$ and $Y 2002$ are not significant, either jointly or individually in any return equation, which strongly supports our claim that $L I B$ was not anticipated and identifies an exogenous regime change.

\section{Quantifying the Effect of Liberalization}

The estimates of Table 7 only indicate the direct effect of each regressor on the corresponding returns to each strategy. From this, we can conclude that, for example, a change in scale triggered by a 1 percent increase of GDP per capita is equivalent to the change due to a 4 percent reduction in population density. Similarly, the positive effect of $L I B$ on the returns to the scale of production is roughly equivalent to a 60 percent increase of the market population. That is, firms in a liberalized market will choose an average scale equivalent to a firm in a 60 percent more populous market pre-liberalization.

These numbers do not necessarily tell the entire story because they do not account for the interdependencies of strategies in the profit function. What is the overall effect of liberalizing the European automobile distribution system on the endogenous variables of our model? In the end, changes in scale of production and/or innovation profiles of firms respond to a combination of direct effects of liberalization and the synergies of interdependent strategies. The answer to this question is complex because of the nonlinear nature of our model, the interactions among parameters, and the existence of correlated unobserved returns.

To evaluate the impact of the increase in competitive pressure therefore, we use our sample of firms to carry out a simulation exercise based on the estimates of Model IV from Table 6. Using the values of the estimated distributional parameters $-\left(\rho_{a h}, \rho_{a y}\right.$, $\left.\rho_{a \pi}, \rho_{h y}, \rho_{h \pi}, \rho_{y \pi}\right)$ and $\left(\sigma_{a}, \sigma_{h}, \sigma_{y}, \sigma_{\pi}\right)$ - of Model IV we generate 2,000 random draws of the remaining parameters of the model from their sampling distribution (given by the estimated coefficients and the covariance matrix of estimates). For each of these draws we generate 150 draws of unobserved returns $\left(\epsilon_{a i}, \epsilon_{h i}, \epsilon_{y i}, \epsilon_{\pi i}\right)$, which are jointly distributed according to a multivariate normal distribution with an expected value of 0 and a covariance matrix given by our estimates of the correlation coefficients $\left(\rho_{a h}\right.$, $\left.\rho_{a y}, \rho_{a \pi}, \rho_{h y}, \rho_{h \pi}, \rho_{y \pi}\right)$ and standard deviations $\left(\sigma_{a}, \sigma_{h}, \sigma_{y}, \sigma_{\pi}\right)$ in Model IV of Table 6 . We then compute the predicted choices of scale, adoption of product and process innovations, and profit realizations $\left(x_{a i}, x_{h i}, x_{y i}, \pi_{i}\right)$ for every firm before the liberalization, i.e., when $L I B=0$, for each of the 300,000 scenarios. We then repeat the analysis adding the estimated value of $L I B$ to the return to each strategy and recompute all optimal choices after the liberalization, i.e., when $L I B=1$. The difference indicates the overall effect that liberalization has on each element of interest of the model.

Table 8 presents the overall effect of liberalization on the endogenous variables. In 
TABLE 8-Simulation OF THE LIBERALIZATION EFFECT: DISTRIBUTION PERCENTILES

\begin{tabular}{|c|c|c|c|c|c|c|c|}
\hline & \multirow[b]{2}{*}{ Mean } & \multicolumn{4}{|c|}{ Percentiles } & \multirow[b]{2}{*}{ 95th } & \multirow[b]{2}{*}{$\operatorname{Pr}(<0)$} \\
\hline & & 5 th & 25 th & Median & 75th & & \\
\hline \multicolumn{8}{|l|}{ Total Effects } \\
\hline$x_{y}$ (percent) & 23.09 & 8.60 & 17.54 & 23.33 & 28.78 & 37.01 & 0.65 \\
\hline$x_{a}$ & -2.00 & -5.38 & -3.38 & -1.95 & -0.73 & 1.56 & 83.65 \\
\hline$x_{h}$ & 4.89 & 1.65 & 3.71 & 4.85 & 6.14 & 7.92 & 0.55 \\
\hline$\pi(1000 €)$ & 0.34 & -2.12 & -0.75 & 0.34 & 1.36 & 2.87 & 41.10 \\
\hline None & -2.46 & -3.86 & -3.05 & -2.46 & -1.88 & -1.02 & 99.80 \\
\hline Only APPS & -2.43 & -5.53 & -3.66 & -2.41 & -1.30 & 0.72 & 91.25 \\
\hline Only HR & 4.46 & 1.00 & 3.16 & 4.43 & 5.80 & 7.80 & 2.10 \\
\hline Both & 0.43 & -0.16 & 0.20 & 0.43 & 0.67 & 1.03 & 11.45 \\
\hline \multicolumn{8}{|l|}{ Direct Effects } \\
\hline$x_{y}$ (percent) & 26.60 & 13.47 & 21.04 & 26.69 & 31.84 & 40.42 & 0.15 \\
\hline$x_{a}$ & -0.13 & -2.38 & -1.08 & -0.11 & 0.75 & 2.11 & 53.25 \\
\hline$x_{h}$ & 2.99 & 1.47 & 2.37 & 2.99 & 3.62 & 4.50 & 0.00 \\
\hline$\pi(1000 €)$ & 0.67 & -2.62 & -0.68 & 0.66 & 2.02 & 3.93 & 36.25 \\
\hline None & -2.27 & -3.65 & -2.85 & -2.29 & -1.70 & -0.82 & 99.60 \\
\hline Only APPS & -0.72 & -1.34 & -0.93 & -0.70 & -0.50 & -0.17 & 97.80 \\
\hline Only HR & 2.40 & 0.57 & 1.65 & 2.38 & 3.11 & 4.29 & 1.15 \\
\hline Both & 0.59 & -1.48 & -0.22 & 0.65 & 1.41 & 2.50 & 31.25 \\
\hline \multicolumn{8}{|c|}{ Complementarities Effects } \\
\hline$x_{y}$ (percent) & -3.51 & -9.89 & -5.68 & -3.40 & -1.32 & 2.60 & 84.70 \\
\hline$x_{a}$ & -1.88 & -3.82 & -2.51 & -1.78 & -1.19 & -0.13 & 96.15 \\
\hline$x_{h}$ & 1.90 & -0.79 & 0.92 & 1.85 & 2.94 & 4.52 & 10.95 \\
\hline$\pi(1000 €)$ & -0.34 & -2.34 & -1.18 & -0.38 & 0.49 & 1.79 & 61.55 \\
\hline None & -0.19 & -0.35 & -0.25 & -0.19 & -0.13 & -0.04 & 98.35 \\
\hline Only APPS & -1.71 & -4.36 & -2.73 & -1.65 & -0.73 & 0.95 & 87.10 \\
\hline Only HR & 2.07 & 0.28 & 1.35 & 1.99 & 2.71 & 4.04 & 2.85 \\
\hline Both & -0.16 & -1.58 & -0.79 & -0.20 & 0.46 & 1.36 & 58.40 \\
\hline
\end{tabular}

Empirical distribution of the direct, indirect, and total effects of 300,000 simulations. They measure the percent change in the scale before and after the liberalization. Profits are measured in thousand of euros. All other variables are changes in probabilities $(\times 100)$. The rightmost column shows the empirical probability $(\times 100)$ that the corresponding effect is negative.

addition to averaging over the 300,000 simulations, Table 8 documents their empirical distribution by reporting the percentiles of the effect of liberalization on each variable. The range defined by the 5 percent and 95 percent percentiles is the 90 percent confidence interval of the empirical distribution of the effect of liberalization.

Table 8 decomposes the total effects of liberalization into those derived under the assumption of independent strategies and those due to complementarity. The total effects are the result of evaluating exactly Model IV of Table 6 . The effects under independence ignore any synergy due to complementarity; i.e., we evaluate Model IV of Table 6 but restrict $\delta_{a h}=\delta_{a y}=\delta_{h y}=0$. The complementarity effects are simply computed as the difference between the other two. Consider the case of profits as an example. The mean increase in profits after the liberalization amounts to $335 €$. The mean direct effect of liberalization reaches $673 €$ but mean profit synergies due to complementarities 
TABLE 9-SIMULATION: OTHER EXOGENOUS COVARIATES

\begin{tabular}{|c|c|c|c|c|c|c|c|c|}
\hline & \multicolumn{2}{|c|}{$\ln (G D P p c)$} & \multicolumn{2}{|c|}{$\ln ($ Density $)$} & \multicolumn{2}{|c|}{$\ln ($ Population $)$} & \multicolumn{2}{|c|}{ Paris } \\
\hline & Mean & S.D. & Mean & S.D. & Mean & S.D. & Mean & S.D. \\
\hline$x_{y}$ (percent) & 10.30 & 5.47 & -2.36 & 1.50 & 3.97 & 2.26 & 43.22 & 68.39 \\
\hline$x_{a}$ & 0.32 & 1.02 & 0.14 & 0.24 & -0.87 & 0.44 & 17.77 & 15.32 \\
\hline$x_{h}$ & -2.93 & 0.98 & 0.19 & 0.27 & 0.53 & 0.41 & 13.23 & 12.14 \\
\hline$\pi(1000 €)$ & 3.18 & 0.87 & -0.38 & 0.32 & 0.35 & 0.37 & 0.09 & 15.07 \\
\hline None & 2.11 & 0.50 & -0.25 & 0.24 & 0.22 & 0.25 & -21.17 & 9.45 \\
\hline Only APPS & 0.83 & 0.93 & 0.07 & 0.22 & -0.75 & 0.40 & 7.94 & 11.51 \\
\hline Only HR & -2.42 & 1.00 & 0.11 & 0.27 & 0.65 & 0.42 & 3.39 & 11.54 \\
\hline Both & -0.51 & 0.21 & 0.08 & 0.11 & -0.12 & 0.12 & 9.83 & 6.60 \\
\hline
\end{tabular}

Mean and standard deviation of after changing the continuous exogenous variables by 10 percent as well as the Paris dummy.

amount to $-338 €$. There is substantial heterogeneity in profits across firms regarding the liberalization of the European automobile distribution system. While the bottom 5 percent dealer loses about $2,000 €$ the top 95 percent increases profits by almost 3,000€. Despite this heterogeneity of effects across firms, the increase in scale, the probability of adopting HR software, the probability of only adopting HR software, and the probability of not adopting any software at all show unambiguous signs. These first three effects are consistently positive (only negative with probability $0.0065,0.0055$, and 0.0210 , respectively) while almost every firm (excluding only 0.20 percent of them) is more likely to adopt some software after the liberalization of the European automobile distribution system. This strongly suggests that liberalization really did have a tangible effect on firm behavior.

Removal of the exclusive territory restraint has a positive direct effect on scale (about 27 percent) and on the probability of adopting the HR software (about 3 percent). HR and APPS are strong substitutes, thus triggering a reduction in the probability of adoption of APPS software of almost 2 percent. This in turn reduces the effect of adoption of $L I B$ on scale by 4 percent as scale and APPS are complements. Overall, LIB increases the scale by 23 percent and the probability of adoption of HR software by 5 percent.

Finally, Table 9 reports the mean and standard deviation of the total effects of changes of all other exogenous variables. Income per capita has an overall significant positive effect on the scale and profits while reducing the probability of adopting HR software. More competition as measured by population density only has a marginal negative total effect on scale. The size of the market as measured by its population positively affects the scale of production and reduces the probability of adopting APPS software. The effects of being situated in Paris are large but also very dispersed. The only one that appears to be significant is the reduction in the probability of not adopting any software.

\section{Concluding Remarks}

In this paper, we study the French automobile market between 2000 and 2004 and in particular, the adoption of two software technologies by car dealers following the de 
facto removal of the exclusive territory restraint following the change in regulation of the European automobile distribution system in September 2002. Our econometric model integrates for the first time the adoption and productivity approaches long discussed in the innovation and management literature for the past two decades and makes use of a number of unique features of our data to identify an increase in competition within the setting of a well-defined single industry.

First, our paper makes use of an exogenous regime shift to identify the effect of increasing competitive pressure on the decision to adopt potentially interdependent innovations. Moreover, we estimate an equilibrium model in which firms choose not only whether to adopt innovations but also their scale of production, which is often treated as exogenous in most empirical studies of innovation activity. The estimation relies on a flexible specification of the profit function and the associated optimality conditions that characterize the optimal scale and innovation profile of each firm. Our equilibrium approach lets us recover the structural parameters of the model from the observed production and innovation decisions of firms, including those pertaining to the payoff synergies associated to the simultaneous use of different strategies. Adding profit information helps us control for the effect of other strategies that firms may use but are unknown to us. We also assume that returns may incorporate an unobserved firm-specific component. By assuming these to be distributed as unrestricted multivariate normal variables, we are able not only to obtain maximum likelihood estimates robust to unobserved heterogeneity, but also to estimate for the first time the "Random Practice Model" proposed by Athey and Stern (1998) to study complementarities.

Our results indicate that an increase in competitive pressure leads to an expansion in the scale of dealerships and increases the returns to adopting HR software (independently of the size of the dealership). We also find that complementarities exist and are robust to firms' unobserved heterogeneity associated to the returns to each strategy. Scale and APPS software are complements while APPS and HR softwares are substitutes. The combination of these results suggests that dealers will specialize in one of the two technologies available to them once the environment they operate in becomes more competitive. This result is reminiscent of the argument put forward by Cohen and Klepper (1996) and suggests that HR software may have better appropriability features than APPS software. Another interesting result we obtain is that the increased competition that characterizes more densely populated markets - e.g., Syverson (2004) — favors the adoption of both software types, while population density has a negative effect on the scale of dealerships as storage costs are quite important in the car dealership industry,

The flexible econometric approach we develop in this paper allows us to identify the different channels through which competition affects the adoption of new technologies. Specifically, we document the existence of complementarities and the fact that the larger optimal scale following an increase in competitive pressure triggers an increase in the rate of adoption of HR software, which in turn reduces the profitability of APPS software. Similar results, if confirmed in other settings, are of interest to policymakers who will have to form ex-ante priors about the social welfare implications of specific types of innovations, as a policy shift may affect innovation adoption in different ways depending on the magnitude of payoff synergies among different strategies. More generally, the notion 
that the adoption of different innovations is likely to be a joint decision with scale and that adoption decisions may substitute for each other implies that future research should take into account these complementarities to adequately study the innovation adoption behavior of firms.

\section{Appendix: Data Sources}

The dataset we use is built from a large firm-level database on the usage of Information and Communication Technologies (ICT). Specifically, the data contain annual information on the software used in about 4,000 companies in a wide variety of industries. We merge the software data with other data sets including firm specific accounting information, as well as socioeconomic and demographic data from publicly available sources:

1) ICT data is collected by Harte-Hanks $(H H)$, a worldwide direct marketing company providing information on computer, software and IT staff usage to clients such as IBM and Oracle for their direct marketing purposes. The data is collected by European and US based call centers. Data include numbers of PCs, servers, and mainframes, the size of the IT department and its functions, as well as brand, version, and use of specific software. The data is provided annually per site (i.e., for each address). In our empirical setting, most of the firms have only one site so we treat sites and firms as equivalent. Further, we believe that this is justified since decisions about the introduction of specific software programs (as specified below) is likely to take place at the site rather than the corporate level.

2) The data set $A M A D E U S$ contains the financial accounts of a large number of companies registered in France. One of the key advantages of using AMADEUS is that it contains data on listed as well as unlisted companies. This is particularly useful because it also allows us to study the adoption behavior of small and medium sized firms and not only large ones. Reporting regulations in France ensure that we have access to a large amount of financial information, including turnover, employees, tangible assets, costs, and profits.

3) French socioeconomic and demographic data is available from the French Statistical Office (INSEE). We collect dèpartement level data on gross domestic product (GDP) and the Population to proxy for market size. We also collected the surface area of these dèpartements to obtain a measure of population density for these markets and identified dèpartements containing large cities (Paris, Marseille, Lyon, Toulouse, and Nice all exceed 300,000 inhabitants), to define markets with an important Urban influence.

Harte-Hanks surveys firms based on a repeated process of comparing the firms already in the sample with the overall population of firms available from public sources. Firms with over 100 employees as well as subsidiaries of large firms (such as company-owned car dealerships) are then targeted for inclusion in the sample. For larger firms, HarteHanks therefore target a census of active firms with more than 100 employees, with smaller firms remaining in the sample if they have shrunk but once had more than 100 
employees or if they are a subsidiary of a larger firm. If a targeted firm answers a sufficient number of questions on their IT use (usually above 60-80 percent), it is included in the database. There is no indication that the firms refusing to answer outright or not answering enough questions are significantly different from the ones that do, suggesting that inclusion in the sample given the firm was in the sampling frame is random. The sampling process described above is consistent across different years, so that our sample consists of a similar selection of larger-than-average firms each year. ${ }^{32}$

Our sample includes either larger dealers or the headquarters of dealership chains. While the number of employees in a single dealership rarely exceeds 100 , the average number of employees in a dealership chain among the top 50 dealer groups in 2003 was $750 .{ }^{33}$ Software is typically adopted in a coordinated fashion across different sites in a chain, suggesting that we are using the appropriate unit of analysis for studying the adoption of interdependent software. These larger firms are among those who survive the restructuring of the industry post-regulation and thus the include those business units for which the adoption of innovations is a relevant decision variable. Smaller dealers only contemplated leaving the industry, and so they had most likely not been innovating before 2002. ${ }^{34}$

\section{REFERENCES}

Aghion, Philippe, Richard W. Blundell, Rachel Griffith, Peter Howitt, and Susan Prantl. 2004. "Entry and Productivity Growth: Evidence from Microlevel Panel Data." Journal of the European Economic Association, 2(2-3): 265-276.

Arora, Ashish, and Alfonso Gambardella. 1990. "Complementarity and External Linkages: The Strategies of the Large Firms in Biotechnology." The Journal of Industrial Economics, 38(4): 361-379.

Arrow, Kenneth J. 1962. "Economic Welfare and the Allocation of Resources for Inventions." In The Rate and Direction of Inventive Activity, ed. Richard R. Nelson, 609-626. Princeton, NJ: Princeton University Press.

Athey, Susan C., and Scott Stern. 1998. "An Empirical Framework for Testing Theories About Complementarity in Organizational Design.” NBER Working Paper 6600.

Athey, Susan C., and Scott Stern. 2002. "The Impact of Information Technology on Emergency Health Care Outcomes.” RAND Journal of Economics, 33(3): 399-432.

\footnotetext{
${ }^{32}$ Harte-Hanks' clients are typically large high-technology firms like IBM and Cisco. They use the information gathered to base their commercial decisions on, thus ensuring a high quality and accuracy of the data as their representatives would quickly find out during a sales call if Harte-Hanks' information was inaccurate. While clients do suggest including or dropping questions on particular technologies to maintain relevancy of their data (leading to, for example, exclusion of technologies that have diffused completely such as word processing software, or technologies that are not marketed actively anymore such as Computer-Aided Design tools), the clients do not influence the sampling process. A firm's propensity to purchase software from any of Harte-Hanks' clients, which could conceivably be another source of selection bias, does not play a role here.

${ }^{33}$ See page 56 of the London Economics report mentioned in the text.

${ }^{34}$ See the 2005 KPMG and FH-Gelsenkirchen report "Entwicklungen und Erfolgsfaktoren im Automobilvertrieb" (Recent Developments and Success Factors in Automobile Retailing) conducted by Ferdinand Dudenhöffer, Peter Wiegand, Karsten Neuberger, and Johannes Steinel, available at: http://www.uni-due.de/ hk0378/studien/2005/ EntwicklungenundErfolgsfaktorenimAutomobilvertrieb2005.pdf.
} 
Berry, Steven T. 1992. "Estimation of a Model of Entry in the Airline Industry." Econometrica, 60(4): 889-917.

Bertschek, Irene. 1995. "Product and Process Innovation as a Response to Increasing Imports and Foreign Direct Investment." Journal of Industrial Economics, 43(4): 341357.

Blundell, Richard W., Rachel Griffith, and John Van Reenen. 1999. "Market Share, Market Value and Innovation in a Panel of British Manufacturing Firms." Review of Economic Studies, 66(3): 529-554.

Boone, Jan. 2000a. "Competitive Pressure: The Effects on Investments in Product and Process Innovation." RAND Journal of Economics, 31(3): 549-569.

Boone, Jan. 2000b. "A New Way to Measure Competition." Economic Journal, 118(531): 1245-1261.

Bowden, Roger. 1973. "The Theory of Parametric Identification." Econometrica, 41(6): 1069-1074.

Brenkers, Randy, and Frank Verboven. 2006. "Liberalizing a Distribution System: The European Car Market." Journal of the European Economic Association, 4(1): 216251.

Bresnahan, Timothy F., Erik Brynjolfsson, and Lorin M. Hitt. 2002. "Information Technology, Workplace Organization, and the Demand for Skilled Labor: Firm-Level Evidence." Quarterly Journal of Economics, 117(1): 339-376.

Brown, Bryan W. 1983. "The Identification Problem in Systems Nonlinear in the Variables." Econometrica, 51(1): 175-196.

Carlin, Wendy, Mark E. Schaffer, and Paul Seabright. 2004. "A Minimum of Rivalry: Evidence from Transition Economies on the Importance of Competition for Innovation and Growth." Contributions to Economic Analysis and Policy, 3(1): Article 17.

Cassiman, Bruno, and Reinhilde Veugelers. 2006. "In Search of Complementarity in the Innovation Strategy: Internal R \& D, Cooperation in R \& D, and External Technology Acquisition.” Management Science, 52(1): 68-82.

Cohen, Wesley M., and Steven Klepper. 1996. "Firm Size and the Nature of Innovation Within Industries: The Case of Process and Product R\&D Effort." Review of Economics and Statistics, 78(2): 232-243.

Galdón-Sánchez, José E., and James A. Schmitz. 2002. "Competitive Pressure and Labor Productivity: World Iron-Ore Markets in the 1980's." American Economic Review, 92(4): 1222-1235.

Gilbert, Richard. 2006. "Looking for Mr. Schumpeter: Where Are We in the Competition-Innovation Debate?" In Innovation Policy and the Economy, Vol. 6, ed. Adam B. Jaffe, Josh Lerner, and Scott Stern. Cambridge, MA: MIT Press.

Goldberg, Pinelopi K., and Frank Verboven. 2001. "The Evolution of Price Dispersion in the European Car Market." Review of Economic Studies, 68(4): 811-848.

Holmes, Thomas J., David K. Levine, and James A. Schmitz. 2008. "Monopoly and the Incentive to Innovate When Adoption Involves Switchover Disruptions.” NBER Working Paper 13864. 
Holmström, Bengt, and Paul R. Milgrom. 1994. "The Firm as an Incentive System." American Economic Review, 84(4): 972-991.

Ichniowski, Casey, Kathryn Shaw, and Giovanna Prennushi. 1997. "The Effects of Human Resource Management Practices on Productivity." American Economic Review, 87(3): 291-313.

MacDonald, James M. 1994. "Does Import Competition Force Efficient Production?" Review of Economics and Statistics, 76(4): 721-727.

Mazzeo, Michael J. 2002. "Product Choice and Oligopoly Market Structure." RAND Journal of Economics, 33(2): 221-242.

Milgrom, Paul R., and John Roberts. 1990. "The Economics of Modern Manufacturing: Technology, Strategy, and Organization.” American Economic Review, 80(3): 511528.

Miravete, Eugenio J., and José C. Pernías. 2006. "Innovation Complementarities and Scale of Production." Journal of Industrial Economics, 54(1): 1-29.

Miravete, Eugenio J., and José C. Pernías. 2010. "Testing for Complementarity when Strategies are Dichotomous.” Economics Letters, 106(1): 28-31.

Rey, Patrick, and Joseph Stiglitz. 1995. "The Role of Exclusive Territories in Producers' Competition." RAND Journal of Economics, 26(3): 431-451.

Rothenberg, Thomas J. 1971. "Identification in Parametric Models." Econometrica, 39(3): 577-591.

Schmutzler, Armin. 2010. "The Relation Between Competition and Innovation - Why Is it Such a Mess?" CEPR Discussion Papers 7640.

Schumpeter, Joseph A. 1934. The Theory of Economic Development. Cambridge, MA: Harvard University Press.

Segal, Ilya R., and Michael D. Whinston. 2007. "Antitrust in Innovative Industries." American Economic Review, 97(5): 1703-1730.

Syverson, Chad. 2004. "Market Structure and Productivity: A Concrete Example." Journal of Political Economy, 112(6): 1181-1222.

Verboven, Frank. 1996. "International Price Discrimination in the European Car Market.” RAND Journal of Economics, 27(2): 240-268.

Verboven, Frank. 2008. "Efficiency Enhancing or Anti-Competitive Vertical Restraints: Selective and Exclusive Car Distribution in Europe." In Cases in European Competition Policy: The Economic Analysis, ed. B. Lyons, 219-244. Cambridge, UK: Cambridge University Press.

Vives, Xavier. 2008. "Innovation and Competitive Pressure." Journal of Industrial Economics, 56(3): 419-469.

Wooldridge, Jeffrey M. 2002. Econometric Analysis of Cross Section and Panel Data. Cambridge, MA: MIT Press. 


\section{Mathematical Web Appendix: Likelihood FunCtion}

Profit function (1) includes includes four differentiated structural error components $\left(\epsilon_{a i}, \epsilon_{h i}, \epsilon_{y i}, \epsilon_{\pi i}\right)$, whose realizations uniquely determine the observed optimal choice of $\left(x_{a i}, x_{h i}, x_{y i}, \pi_{i}\right)$. To estimate the model we assume that the vector of unobservable returns follows an unrestricted multivariate normal distribution.

The Joint Density of Scale and Profits.-To write the likelihood function we first condition on the two continuous variables of the model, i.e., scale and profits. First, from equation (3), the unobserved return associated to scale is

$$
\epsilon_{y i}=\gamma x_{y i}-\theta_{y}-\delta_{a y} x_{a i}-\delta_{h y} x_{h i},
$$

and next we rewrite the profit equation (1) as follows

$$
\epsilon_{p i}=\pi_{i}-\theta_{\pi}-\theta_{a} x_{a i}-\theta_{h} x_{h i}-\delta_{a h} x_{a i} x_{h i}+(\gamma / 2) x_{y i}^{2},
$$

where we define $\epsilon_{p i}$ as the total unobserved return to adopting any strategy other than the scale, that is

$$
\epsilon_{p i}=\epsilon_{\pi i}+\epsilon_{a i} x_{a i}+\epsilon_{h i} x_{h i} .
$$

Because of our normality assumptions on the distribution of $\epsilon_{i}$, it follows that $\epsilon_{p i}$ is also normally distributed with zero mean and variance

(A4) $\sigma_{p i}^{2}=\sigma_{\pi}^{2}+\left(\sigma_{a}^{2}+2 \sigma_{a} \sigma_{\pi} \rho_{a \pi}\right) x_{a i}+\left(\sigma_{h}^{2}+2 \sigma_{h} \sigma_{\pi} \rho_{h \pi}\right) x_{h i}+2 \sigma_{a} \sigma_{h} \rho_{a h} x_{a i} x_{h i}$.

Thus, the joint density of $\epsilon_{y i}$ and $\epsilon_{p i}$ is given by

$$
g\left(\epsilon_{y i}, \epsilon_{p i}\right)=\left(\sigma_{y} \sigma_{p i}\right)^{-1} \phi_{2}\left(\epsilon_{y i} / \sigma_{y}, \epsilon_{p i} / \sigma_{p i} ; \rho_{y p i}\right),
$$

where the correlation coefficient between $\epsilon_{y i}$ and $\epsilon_{p i}$ is

$$
\rho_{y p i}=\left(\sigma_{\pi} \rho_{y \pi}+\sigma_{a} \rho_{a y} x_{a i}+\sigma_{h} \rho_{h y} x_{h i}\right) / \sigma_{p i} .
$$

Notice that given the distribution of $\boldsymbol{\epsilon}_{i}$, and making use of (A3), equations (1) and (3) define a transformation from $\left(\epsilon_{y i}, \epsilon_{p i}\right)$ to $\left(x_{y i}, \pi_{i}\right)$. The determinant of the Jacobian of the inverse transformation given by equations (A1) and (A2) is

$$
\boldsymbol{J}=\left|\begin{array}{ll}
\frac{\partial \epsilon_{y i}}{\partial x_{y i}} & \frac{\partial \epsilon_{y i}}{\partial \pi_{i}} \\
\frac{\partial \epsilon_{p i}}{\partial x_{y i}} & \frac{\partial \epsilon_{p i}}{\partial \pi_{i}}
\end{array}\right|=\left|\begin{array}{cc}
\gamma & 0 \\
-\gamma x_{y i} & 1
\end{array}\right|=\gamma>0 .
$$

The determinant of the Jacobian of the inverse transformation is strictly positive because of the assumption that profits are concave in $x_{y i}$. Thus, equations (1) and (3) 
define a one-to-one transformation from $\left(\epsilon_{y i}, \epsilon_{p i}\right)$ to $\left(x_{y i}, \pi_{i}\right)$ so that the joint density of $\left(x_{y i}, \pi_{i}\right)$ is

$$
g\left(x_{y i}, \pi_{i}\right)=\left(\sigma_{y} \sigma_{p i}\right)^{-1} \phi_{2}\left(\epsilon_{y i} / \sigma_{y}, \epsilon_{p i} / \sigma_{p i} ; \rho_{y p i}\right) \gamma,
$$

which depends on the values of $x_{a i}$ and $x_{h i}$ through equations (A1) and (A2).

Probability of Innovation Profile Choice.-The adoption of innovations is determined by conditions (13a)-(13c), which also depends on the unobserved returns to scale and innovations. Therefore, we first rewrite those equations conditioning on $\epsilon_{y i}$ and $\epsilon_{p i}$, and second, we derive the probabilities of observing each of the four possible innovation profiles. Thus, we write

$$
\begin{aligned}
& \epsilon_{a i}=m_{a i}+\epsilon_{a . y p i}, \\
& \epsilon_{h i}=m_{h i}+\epsilon_{h . y p i},
\end{aligned}
$$

where $m_{a i}$ and $m_{h i}$, are the expectations of $\epsilon_{a i}$ and $\epsilon_{h i}$, conditional on $\epsilon_{y i}$ and $\epsilon_{p i}$ respectively, i.e.,

$$
\begin{aligned}
& m_{a i}=\sigma_{a} \frac{\left(\rho_{a y}-\rho_{a p i} \rho_{y p i}\right) \epsilon_{y i} / \sigma_{y}+\left(\rho_{a p i}-\rho_{a y} \rho_{y p i}\right) \epsilon_{p i} / \sigma_{p i}}{1-\rho_{y p i}^{2}}, \\
& m_{h i}=\sigma_{h} \frac{\left(\rho_{h y}-\rho_{h p i} \rho_{y p i}\right) \epsilon_{y i} / \sigma_{y}+\left(\rho_{h p i}-\rho_{h y} \rho_{y p i}\right) \epsilon_{p i} / \sigma_{p i}}{1-\rho_{y p i}^{2}},
\end{aligned}
$$

and where the correlations between $\epsilon_{p i}$ and $\epsilon_{a i}, \epsilon_{h i}$ are

$$
\begin{aligned}
& \rho_{a p i}=\left(\sigma_{\pi} \rho_{a \pi}+\sigma_{a} x_{a i}+\sigma_{h} \rho_{a h} x_{h i}\right) / \sigma_{p i}, \\
& \rho_{h p i}=\left(\sigma_{\pi} \rho_{h \pi}+\sigma_{h} x_{h i}+\sigma_{a} \rho_{a h} x_{h i}\right) / \sigma_{p i},
\end{aligned}
$$

so that $\epsilon_{a . y p i}, \epsilon_{h . y p i}$ are normal variables that, by construction, are independent of $\epsilon_{y i}$ and $\epsilon_{p i}$. They have variances

$$
\begin{aligned}
& \sigma_{a . y p i}^{2}=\sigma_{a}^{2}\left(1-\frac{\rho_{a y}^{2}+\rho_{a p i}^{2}-2 \rho_{y p i} \rho_{a y} \rho_{a p i}}{1-\rho_{y p i}^{2}}\right), \\
& \sigma_{h . y p i}^{2}=\sigma_{h}^{2}\left(1-\frac{\rho_{h y}^{2}+\rho_{h p i}^{2}-2 \rho_{y p i} \rho_{h y} \rho_{h p i}}{1-\rho_{y p i}^{2}}\right),
\end{aligned}
$$

and covariance given by

$$
\begin{aligned}
& \operatorname{cov}\left(\epsilon_{a . y p i}, \epsilon_{h . y p i}\right)= \\
& \quad \sigma_{a} \sigma_{h}\left(\rho_{a h}-\frac{\rho_{a y} \rho_{h y}+\rho_{a p i} \rho_{h p i}-\rho_{y p i}\left(\rho_{a y} \rho_{h p i}+\rho_{a p i} \rho_{h y}\right)}{1-\rho_{y p i}^{2}}\right) .
\end{aligned}
$$


Next, we substitute the unobserved returns to innovations given by equations (A9a) and (A9b) into conditions (13a)-(13c) and after rearranging terms we get

$$
\begin{aligned}
& q_{a i} \epsilon_{a . y p i}>-q_{a i}\left(k_{a i}+\delta x_{h i}\right), \\
& q_{h i} \epsilon_{h . y p i}>-q_{h i}\left(k_{h i}+\delta x_{a i}\right), \\
& q_{h i} \epsilon_{\text {s.yp } i}>-q_{h i}\left[k_{h i}+\delta / 2+s_{i}\left(k_{a i}+\delta / 2\right)\right],
\end{aligned}
$$

where

$$
\begin{aligned}
k_{a i} & =\kappa_{a i}+m_{a i}, \\
k_{h i} & =\kappa_{h i}+m_{h i}, \\
\epsilon_{\text {s.yp } i} & =\epsilon_{h . y p i}+s_{i} \epsilon_{a . y p i},
\end{aligned}
$$

which is a normal variable with zero mean and variance equal to

$$
\sigma_{s . y p i}^{2}=\sigma_{a . y p i}^{2}+\sigma_{h . y p i}^{2}+2 s_{i} \sigma_{a . y p i} \sigma_{h . y p i} \rho_{a h . y p i} .
$$

Furthermore, the correlation coefficients among $\epsilon_{s . y p i}$ and $\epsilon_{a . y p i}, \epsilon_{h . y p i}$ are

$$
\begin{aligned}
& \rho_{\text {as.yp } i}=\left(\sigma_{\text {h.ypi }} \rho_{\text {ah.yp } i}+s_{i} \sigma_{a . y p i}\right) / \sigma_{\text {s.yp }}, \\
& \rho_{\text {hs.yp } i}=\left(\sigma_{\text {h.yp } i}+s_{i} \sigma_{\text {a.ypi }} \rho_{\text {ah.yp } i}\right) / \sigma_{\text {s.yp } i} .
\end{aligned}
$$

Consider now the probability that firm $i$ adopts both innovations, i.e., $x_{a i}=1$, and $x_{h i}=1$. Then, conditional on $\epsilon_{y i}$ and $\epsilon_{p i}$, conditions (8a)-(8c) must hold; that is

$$
\begin{aligned}
& \epsilon_{a . y p i}>-k_{a i}-\delta, \\
& \epsilon_{h . y p i}>-k_{h i}-\delta, \\
& \epsilon_{\text {s.yp } i}>-k_{a i}-k_{h i}-\delta .
\end{aligned}
$$

There are two cases of interest depending on the value of $\delta$ :

1) $\delta \leq 0$. In this case the last of the above inequalities does not bind. This case corresponds to the bottom of Figure 1 where $S_{i}(1,1)$ is rectangular and thus, the probability of adopting both innovations becomes

$$
\operatorname{Pr}\left(x_{a i}=1, x_{h i}=1\right)=\operatorname{Pr}\left(\epsilon_{a . y p i}>-k_{a i}-\delta, \epsilon_{h . y p i}>-k_{h i}-\delta\right),
$$

which, given our assumption of joint normal distribution, leads to

$$
\operatorname{Pr}\left(x_{a i}=1, x_{h i}=1\right)=\Phi_{2}\left(\frac{k_{a i}+\delta}{\sigma_{a . y p i}}, \frac{k_{h i}+\delta}{\sigma_{h . y p i}} ; \rho_{a h . y p i}\right) .
$$

$\Phi_{2}(\cdot ; \rho)$ is the cumulative density function of a standard bivariate normal distribution with correlation coefficient $\rho$, which in this case is the correlation coefficient between $\epsilon_{a . y p i}$ and $\epsilon_{h . y p i}$ (or, equivalently, the correlation between $\epsilon_{a i}$ and $\epsilon_{h i}$ conditional 
on $\left.\epsilon_{y i}, \epsilon_{p i}\right)$ :

$$
\rho_{a h . y p i}=\operatorname{cov}\left(\epsilon_{a . y p i}, \epsilon_{h . y p i}\right) /\left(\sigma_{a . y p i} \sigma_{h . y p i}\right) .
$$

2) $\delta>0$. Now the three inequalities (A18a)-(A18c) bind. This case corresponds to the top of Figure 1 where $S_{i}(1,1)$ is no longer rectangular. To compute the probability of adopting both innovations, we split the region defined by the three inequalities (A18a)-(A18c) into the following two disjoint areas defined by

$$
\begin{aligned}
& \epsilon_{a . y p i}>-k_{a i}, \\
& \epsilon_{h . y p i}>-k_{h i}-\delta,
\end{aligned}
$$

and by

$$
\begin{aligned}
-k_{a i} & >\epsilon_{a . y p i}>-k_{a i}-\delta, \\
\epsilon_{\text {s.ypi }} & >-k_{a i}-k_{h i}-\delta,
\end{aligned}
$$

where the second set of inequalities make use of a change of basis so that the integration region defined in the $\left(\epsilon_{a . y p i}, \epsilon_{s . y p i}\right)$ plane is rectangular. Integrating the probability density function of $\left(\epsilon_{a . y p i}, \epsilon_{h . y p i}\right)$ over the area defined by (A22a) and (A22b) we get

$$
\begin{aligned}
& \operatorname{Pr}\left(\epsilon_{a . y p i}>-k_{a i}, \epsilon_{h . y p i}>-k_{h i}-\delta\right)= \\
& \Phi_{2}\left(\frac{k_{a i}}{\sigma_{a . y p i}}, \frac{k_{h i}+\delta}{\sigma_{h . y p i}} ; \rho_{a h . y p i}\right),
\end{aligned}
$$

and integrating the probability density function of $\left(\epsilon_{a . y p i}, \epsilon_{s . y p i}\right)$ over the region defined by (A23a)-(A23b) we have

$$
\begin{aligned}
& \operatorname{Pr}\left(-k_{a i}>\epsilon_{a . y p i}>-k_{a i}-\delta, \epsilon_{s . y p i}>-k_{a i}-k_{h i}-\delta\right)= \\
& \begin{array}{c}
\Phi_{2}\left(\frac{k_{a i}+\delta}{\sigma_{a . y p i}}, \frac{k_{a i}+k_{h i}+\delta}{\sigma_{s . y p i}} ; \rho_{a s . y p i}\right)- \\
\Phi_{2}\left(\frac{k_{a i}}{\sigma_{a . y p i}}, \frac{k_{a i}+k_{h i}+\delta}{\sigma_{s . y p i}} ; \rho_{a s . y p i}\right) .
\end{array}
\end{aligned}
$$

Finally, combining (A24), and (A25) we obtain the probability that a firm engages in both product and process innovation as

$$
\begin{gathered}
\operatorname{Pr}\left(x_{a i}=1, x_{h i}=1\right)=\Phi_{2}\left(\frac{k_{a i}}{\sigma_{a . y p i}}, \frac{k_{h i}+\delta}{\sigma_{h . y p i}} ; \rho_{a h . y p i}\right)+ \\
\Phi_{2}\left(\frac{k_{a i}+\delta}{\sigma_{a . y p i}}, \frac{k_{a i}+k_{h i}+\delta}{\sigma_{\text {s.yp }}} ; \rho_{a s . y p i}\right)-
\end{gathered}
$$




$$
\Phi_{2}\left(\frac{k_{a i}}{\sigma_{a . y p i}}, \frac{k_{a i}+k_{h i}+\delta}{\sigma_{s . y p i}} ; \rho_{a s . y p i}\right) .
$$

We can determine the probabilities of adopting each innovative profile in a similar manner. To provide a general notation, let's define the indicator variable $I_{i}$ as

$$
I_{i}=\left\{\begin{array}{lll}
1 & \text { if } \quad s_{i} \delta>0 \\
0 & \text { if } \quad s_{i} \delta \leq 0
\end{array}\right.
$$

Then, since $x_{a i}$ and $x_{h i}$ may take only values in $\{0,1\}$, we have

$$
\begin{aligned}
& \operatorname{Pr}\left(x_{a i}, x_{h i}\right)= \\
& \Phi_{2}\left(q_{a i} \frac{k_{a i}+\delta\left[I_{i}-x_{h i}\left(2 I_{i}-1\right)\right]}{\sigma_{a . y p i}}, q_{h i} \frac{k_{h i}+\delta x_{a i}}{\sigma_{h . y p i}} ; s_{i} \rho_{a h . y p i}\right) \\
& +I_{i} s_{i}\left[\Phi_{2}\left(\frac{k_{a i}+\delta}{\sigma_{a . y p i}}, q_{h i} \frac{k_{h i}+\delta / 2+s_{i}\left(k_{a i}+\delta / 2\right)}{\sigma_{s . y p i}} ; q_{h i} \rho_{a s . y p i}\right)\right. \\
& \left.\quad-\Phi_{2}\left(\frac{k_{a i}}{\sigma_{a . y p i}}, q_{h i} \frac{k_{h i}+\delta / 2+s_{i}\left(2 k_{a i}+\delta / 2\right)}{\sigma_{s . y p i}} ; q_{h i} \rho_{a s . y p i}\right)\right] .
\end{aligned}
$$

The Likelihood Function.-Finally, we write the unconditional probability of observing a firm with specific strategy choices by multiplying the conditional probability of a given innovation profile (A28), by the join density of the distribution of scale and profits from other activities (A8), to obtain the contribution of observation $i$ to the logarithm of the likelihood function

$$
\begin{aligned}
& \ln L_{i}\left(\Theta \mid x_{y i}, \pi_{i}, x_{a i}, x_{h i}\right)= \\
& \ln \gamma-\ln \sigma_{y}-\ln \sigma_{p i}+\ln \phi_{2}\left(\epsilon_{y i} / \sigma_{y}, \epsilon_{p i} / \sigma_{p i} ; \rho_{y p i}\right)+ \\
& \ln \left[\Phi_{2}\left(q_{a i} \frac{k_{a i}+\delta\left[I_{i}-x_{h i}\left(2 I_{i}-1\right)\right]}{\sigma_{a . y p i}}, q_{h i} \frac{k_{h i}+\delta x_{a i}}{\sigma_{h . y p i}} ; s_{i} \rho_{a h . y p i}\right)+\right. \\
& I_{i} s_{i} \Phi_{2}\left(\frac{k_{a i}+\delta}{\sigma_{a . y p i}}, q_{h i} \frac{k_{h i}+\delta / 2+s_{i}\left(k_{a i}+\delta / 2\right)}{\sigma_{s . y p i}} ; q_{h i} \rho_{a s . y p i}\right)- \\
& \left.I_{i} s_{i} \Phi_{2}\left(\frac{k_{a i}}{\sigma_{a . y p i}}, q_{h i} \frac{k_{h i}+\delta / 2+s_{i}\left(2 k_{a i}+\delta / 2\right)}{\sigma_{s . y p i}} ; q_{h i} \rho_{a s . y p i}\right)\right],
\end{aligned}
$$

where $\boldsymbol{\Theta}=\left(\theta_{a}, \theta_{h}, \theta_{y}, \theta_{\pi}, \delta_{a h}, \delta_{a y}, \delta_{h y}, \gamma, \sigma_{a}, \sigma_{h}, \sigma_{y}, \sigma_{\pi}, \rho_{a h}, \rho_{a y}, \rho_{a \pi}, \rho_{h y}, \rho_{h \pi}\right.$, $\left.\rho_{y \pi}\right)^{\prime}$ is the vector of parameters of the model.

Normalization.-Directly maximizing the log-likelihood function (A29) with respect to the elements of parameter vector $\boldsymbol{\Theta}$ is complicated by the non-negativity of some parameters (as is the case of $\gamma$ and the standard deviations $\sigma_{a}, \sigma_{h}, \sigma_{y}$, and $\sigma_{\pi}$ ) and by the restrictions on the correlation coefficients $\left(\rho_{a h}, \rho_{a y}, \ldots, \rho_{y \pi}\right)$ imposed by the positive 
definiteness of correlation matrix $\boldsymbol{R}$ given in equation (15). We thus reparameterize the likelihood function in order to avoid these restrictions. First, we define the parameter $\varphi$ as

$$
\varphi=\ln (\gamma)
$$

so that $\varphi$ is unrestricted although $\gamma$ is restricted to be positive. Second, we can write the covariance matrix of unobservables $\left(\epsilon_{a i}, \epsilon_{h i}, \epsilon_{y i}, \epsilon_{\pi i}\right)^{\prime}$ as

$$
\Sigma=D R D
$$

where $\boldsymbol{D}$ is a diagonal matrix whose main diagonal entries are $\left(\sigma_{a}, \sigma_{h}, \sigma_{y}, \sigma_{\pi}\right)$ and $\boldsymbol{R}$ is the correlation matrix given in equation (15). Consider now the Cholesky decomposition of $\Sigma$,

$$
\Sigma=L^{\prime}
$$

where $\boldsymbol{L}$ is a lower triangular matrix with strictly positive diagonal entries. From $l_{i j}$, the non-zero entries of matrix $\boldsymbol{L}$, we define

$$
\lambda_{i j}= \begin{cases}l_{i j}, & j<i ; i=1, \ldots, 4, \\ \ln \left(l_{i i}\right), & i=1, \ldots, 4 .\end{cases}
$$

The $\lambda_{i j}$ parameters are continuous differentiable functions of the standard deviations and correlation coefficients of the unobservables $\left(\epsilon_{a i}, \epsilon_{h i}, \epsilon_{y i}, \epsilon_{\pi i}\right)^{\prime}$. But, the $\lambda_{i j}$ are not restricted and could take any value. The remaining parameters in $\boldsymbol{\Theta}$, i.e., the direct returns to the choice variables, $\theta_{a}, \theta_{h}, \theta_{y}, \theta_{\pi}$, and the complementarity parameters, $\delta_{a h}$, $\delta_{a y}, \delta_{h y}$, are not restricted.

The above transformations define a function between the unrestricted parameter vector $\boldsymbol{\Theta}^{*}=\left(\theta_{a}, \theta_{h}, \theta_{y}, \theta_{\pi}, \delta_{a h}, \delta_{a y}, \delta_{h y}, \varphi, \lambda_{11}, \lambda_{21}, \lambda_{22}, \lambda_{31}, \lambda_{32}, \lambda_{33}, \lambda_{41}, \lambda_{42}, \lambda_{43}\right.$, $\left.\lambda_{44}\right)^{\prime}$ and $\Theta$ :

$$
\boldsymbol{\Theta}=c\left(\boldsymbol{\Theta}^{*}\right) .
$$

The log-likelihood function can finally be written as

$$
\begin{aligned}
& \ln L_{i}\left(\boldsymbol{\Theta} \mid x_{y i}, \pi_{i}, x_{a i}, x_{h i}\right)= \\
& \ln L_{i}\left(c\left(\boldsymbol{\Theta}^{*}\right) \mid x_{y i}, \pi_{i}, x_{a i}, x_{h i}\right)=\ln L_{i}^{*}\left(\boldsymbol{\Theta}^{*} \mid x_{y i}, \pi_{i}, x_{a i}, x_{h i}\right)
\end{aligned}
$$

so that we obtain our estimates by maximizing $\ln L_{i}^{*}$ with respect to $\widehat{\boldsymbol{\Theta}}^{*}$ and applying the transformation $\widehat{\boldsymbol{\Theta}}=c\left(\widehat{\boldsymbol{\Theta}}^{*}\right)$.

Simulations. - The simulations are performed by drawing $\Theta^{*^{(r)}}$ from a multivariate normal distribution with mean $\widehat{\boldsymbol{\Theta}}^{*}$ and a cluster-robust covariance matrix estimator of 
$\widehat{\boldsymbol{\Theta}}^{*}$. For each draw of the parameter vector, $\boldsymbol{\Theta}^{(r)}=c\left(\boldsymbol{\Theta}^{*}(r)\right)$, we perform random draws of $\left(\epsilon_{a i}, \epsilon_{h i}, \epsilon_{y i}, \epsilon_{\pi i}\right)^{\prime}$ for every observation in the sample, using a multivariate normal distribution with mean 0 and covariance matrix $\Sigma^{(r)}$ obtained from the corresponding elements of $\boldsymbol{\Theta}^{(r)}$. Finally, with these simulated sample of the unobservables we solve for the values of the endogenous variables $x_{a i}, x_{h i}, x_{y i}, \pi_{i}$, as discussed in Section II.

This procedure allows us to compute the expected change in the endogenous variables that result from changes in exogenous variables that are discussed in Section III.C. For each scenario we used 2,000 different parameter vectors and for each of those draws we generate 150 random samples. In this way, we take into account the impact of the estimation uncertainty into the simulation results. 